erster Ordnung der grosszelligen Generation, aus welcher die wurmförmigen Spermien hervorgehon. In Figur 49 sind die grossen Centralkörper der Fig. 48 in eine Anzahl Körner zerfallen.

Fig. 50-52. Drei Stadien der Umwandlung einer Spermatide der grosszelligen Generation in eine wurmförmige Spermie.

Die Figuren der T a f e $\mathrm{XXVII}$ sind mit Zeiss' Apochromat $2 \mathrm{~mm}$ (Apertur 1,30) und Ocular 12 unter Benutzung des A b be'schen Zeichenapparates bei Projektion auf halber Objekttischhöhe entworfen. Sie betreffen Spermatocyten der grosszelligen Generation und Umwandlungsstadien der aus ihr hervorgehenden Spermatiden aus dem Hoden von Pygaera bucephala. Die Hoden waren der Puppe entnommen und mit dem Flem ming'schen Chromosmiumessigsiiure-Gemisch fixirt; die Schnitte mit Eiweiss-Wasser aufgeklebt und mit Eisenhämatoxylin gefärbt.

Fig. 53. Spermatocyte erster Ordnung im Ruhestadium.

Fig. 54-59. Erste Reifungstheilung.

Fig. 60-66. Zweite Reifungstheilung.

Fig. 67-69. Drei aufeinanderfolgende Umwandlungsstadien der Spermatide in die Spermie.

\title{
Zur Entwickelung und Verzweigung des Bronchialbaumes der Säugethierlunge ${ }^{1}$ ).
}

\author{
Von
}

Dr. cand. med. u. chir. P. Th. Justesen, Kopenhagen.

Die allererste Anlage der Athmungsorgane wurde im Beginne und Mitte dieses Jahrhunderts von v. Baer, Bis ch off, Remak, Kölliker, Yalan de la Croix und Waters studirt, später ron Kölliker, von Küttner, Stieda, Cadiat und $\mathrm{H}$ is.

Man fand, dass die erste Andeutung der Lungen in einer einfachen Prominenz an der Vorderfäche der Speiseröbre ge-

1) Auszug eines Theiles einer grösseren dänischen, im Drucke noch nicht erschienenen Abhandlung: Bronchier, Bronchioler og Alveoler i Oksens og Oksefosterets Lunge. ${ }^{\text {" }}$ 
Zur Entwickelung und Verzweigung des Bronchialbaumes etc. $\quad 607$

geben sei, ein höckerartiger Vorsprung, der sich erst secundär in zwei Hälften theile, die beiden Lungenanlagen. Die Luftröhre bilde sich von dem mehr kopfwärts liegenden Theile des Oesophagus, indem dieser sich, wie dies besonders $\mathrm{H}$ is genau beschreibt, durch eine von den Seitenwänden hervorwachsende Scheidewand in zwei sagittal hinter einander liegende Röhre theile, von denen die vordere zur Trachea werde.

Hieraus geht also der Satz hervor: „Die Lungen bilden sich, unabhängig von der Luftröhre, am unteren Ende dieser, an der Bifurcatur".

Wie wachsen aber die hiervon ausgehenden Bronchialröhren?

Schon Remak behauptet, dass die Verzweigung eine monopodische sei. v. Baer, der dasselbe Object benutzt hat, den Hühnerembryo nämlich, sieht dagegen die ersten Bronchialgenerationen sich durch einige sich folgende Dichotomien bilden; bei der späteren Entwickelung findet auch er stets monopodische Theilungen.

Mandl nimmt die dichotomische Theilung an, indem er sagt, dass die Bildung neuer Blasen dadurch erfolgt, dass eine primäre Blase sich in zwei oder vier secundäre theilt.

Kölliker scheint sich $R$ e mak anzuschliessen, indem er sagt: „Das Epithelrohr bildet hohle Aussackungen oder Knospen, welche, rasch sich vermehrend, bald in jeder Lunge ein ganzes Biumchen von hohlen Canälen mit kolbig angeschwollenen Enden erzeugen, von welchen dann durch Bildung immer neuer und zahlreicher Knospen endlich das ganze respiratorische Höhlensystem gebildet wird."

Stieda sagt: „Zuerst ist der Canal einfach, dann theilt er sich in Aeste, welche sich abermals theilen, so dass sowohl durch fortgesetzte Theilung als auch durch seitliche Sprossenbildung ein epitheliales, anfangs noch leicht übersehbares Canalsystem entsteht, dessen blinde Endigungen gewöhnlich etwas leicht erweitert sind. Bemerkenswerth ist, dass an denjenigen Stellen, an denen Seitenäste oder Sprossen sich bilden, zuerst eine ganz geringe Vorwölbung der Epithelialwand des Canals erscheint; dieselbe wird allmählich grösser, weiter, zieht sich in die Länge, bis allmählich ein neuer, blind endigender Seitenast entstanden ist."

Küttner wieder meint, dass nur monopodische Processe sich bei Bildung der Bronchialröhrchen abspielen, führt aber des Näheren aus, dass die ursprünglich monopodische Verzweigung unter dem späteren Wachsthume ein dichotomisches Aussehen annimmt. Bei einem 6-7 cm langen Ochsenembryo findet er den Bronchialbaum von drei weiten, kolbenartig endenden Hauptröhren gebildet, von welchen rechtwinklig Zweige abgehen. die ebenso enden. Das Ende des Bronchialrohrs wächst ungetheilt weiter, während Seitenzweige sich bilden und rechtwinklig vom Stamme heraus wachsen. Diese Seitenzweige wachsen 
aber und verzweigen sich reichlicher als der Hauptstamm, und die Verzweigung bekommt daher das Aussehen eines dichotomischen Systems.

Cadiat hat in mehreren Hinsichten originelle Meinungen. Er hat die ganze Entwickelung beim Schafsembryo studirt und ist ersterıs zu der Anschauung gekommen, dass die Bronchen monopodisch wachsen. Es geschieht keine Theilung der angeschwollenen Enden. Die Anschwellung giebt im Gegentheil an, dass die betreffende Röhre ihr Wachsthum beendet hat. Dem Stamme entlang bilden sich dagegen stets neue Seitenzweige. Diese wachsen jetzt eine Zeit, bis auch sie am Ende anschwellen und damit $z u$ wachsen aufhören, und so geht also das Wachsthum des Bronchialbaumes in stets wechselnden Richtungen vor sich. Nur in dieser Weise kann man sich, meint Cadiat, die zahllosen Zweige des erwachsenen Bronchialbaumes erklïren.

A e by hebt schärfer als irgend ein anderer die monopodische Verzweigung als die allein stattfindende hervor. Ja, er ist in dieser Hinsicht so überzengt, dass er, obwohl er die betr. Frage selbst nicht untersucht hat, doch $\mathrm{K} \ddot{0}$ lliker nicht beipflichten will, dass die erste Lungenanlage eine ungetheilte sei. Dann müsste sie nämlich sogleich mit einer dichotomischen Theilung anfangen, um die zwei Hauptbronchen zu bilden, und dies würde mit den Anschauungen A e bys ïber die Theilungsvorgänge des Bronchialbaumes nicht stimmen. Die verschiedenen Meinungen über die Anlage der Lungen besprechend, sagt er: „Ein Organ, das in seinem ganzen, so ungenein consequenten Aufbau nichts von Dichotomie weiss, kann unmöglich einer solchen in seinem ersten, grundlegenden Vorgang huldigen und damit seinen späteren Charakter verleugnen".

$\mathrm{H}$ is, der diese Zeilen citirt, bemerkt daza: ${ }_{n}$ Es ist dies eine Vorstellungsweise etwas transscendenter Natur, und fast scheint mir, als habe sich der verdienstvolle Forscher durch seine die Organe personificirende Sprache zu derselben verleiten lassen".

$\mathrm{H}$ is hat selbstverständlich Recht, wenn er weiter sagt, dass die Wachsthumsbedingungen eines Organes während der verschiedenen Phasen der Entwickelung nicht dieselbe zu sein brauchen, und dass darum die Processe sich ändern können. Obwohl ich mit der Hi s'schen Kritik der A eby'schen Anschauungen über die Bronchialverzweigung ganz einverstanden bin, scheint es mir jedoch, dass der Gedankengang, dass ein Organ auf einer Stufe wahrscheinlieh sich nach denselben Ge- 
setzen entwickelt, die sonst für seine ganze Entwickelung die geltenden sind, mit den Resultaten, die das Studium der Natur in den allermeisten Fällen ergiebt, übereinstimmt. Man darf nicht sagen, dass, wenn es auf einer Stufe sich so und so verhält, dann es auch so auf einer anderen ist, aber wohl, dass so lange wie das Verhültniss hier nicht untersucht ist, der Vorgang; der mit dem ubrigen Charakter des Organes ibereinstimmt, die Wahrscheinlichkeit vor anderen für sich hat.

Diesen Gedankengang A eby's will ich für eine Kritik seiner Anschauungen verwenden, auch in so weit wie $\mathrm{H}$ is diese hat stehen lassen. Ich bin, wie man sehen wird, zu dem Resultate gekommen, dass die Bronchialverzweigung auf allen den Stadien, die ich habe untersuchen können, consequent dichotomisch ist, und ich würde daher als das wahrscheinlichste ansehen, dass dem auch so wäre in den allerfrühesten Stufen, die ich mir nicht habe verschaffen können. Ich werde die Anschauungen Aeby's und $\mathrm{His}$ in dieser Hinsicht genauer besprechen und zu zeigen versuchen, dass ein genügender Beweis dafür, dass der ${ }_{n}$ Stammbronchus" eine monopodische Verzweigung babe, liberhaupt nicht vorliegt. Es ist kein Versuch, die Frage durch unberechtigte Analogiefolgerungen zu lösen, ich will nur behaupten, dass die Frage nicht gelöst ist, weitere Untersuchungen dagegen nöthig sind.

Aeby beginnt sein Buch über den Bronchialbaum folgendermaassen: "Unsere bisherigen Vorstellungen von der Lunge des Säugethieres beruhen auf der Voraussetzung einer dichotomischen Verzweigungsweise ihrer Luftwege. Besonders förderlich für das Verständniss des Organes hat sich dieselbe nicht erwiesen, und ich befürchte keinen Widerspruch, wenn ich das betreffende $K$ apitel als eines der ödesten und undankbarsten der vergleichenden Morphologie bezeichne. Schwächlich, hülflos in eigener Gestaltungskraft erscheint die Lunge wie ein Spielball ihrer Umgebung und ihre jeweilige Gestaltung kaum mehr denn als ein Werk des Zufalls. Die Beziehungen der ungelappten zur gelappten und der an Lappen armen zu der an Lappen reichen liegen völlig im Dunkel, ja es ist kaum noch ein Versuch gemacht worden, solche herzustellen. Der empirischen Form fehlte eben der bewusste Inbalt, ihrem fortwährenden Wechsel der Halt eines leitenden Principes. Das Dogma des dichotomisch getheilten Bronchialbaumes trug die Schuld. In seinem Banne lag selbst die Entwickelungsgoschichte, die sonst wohl zu anderen Ergebnissen hätte führen können, gefang'en." A eb y zeigt, dass der Grundplan des Baues der Lunge derselbe ist für alle Säugethiere.

„Von einem dichotomischen Zerfalle der beiden Luftröhrenäste 
ist nirgends die Rede, und es muss in dieser Hinsicht mit der Ueberlieferung ein für allemal gründlich gebrochen werden. Weit davon entfernt, sich beim Fintritte in die Lungensubstanz aufzulösen, bewahrt ein jeder von ihnen seine volle, individuelle Selbständigkeit, indem er, ohne seine Richtung wesentlich zu ändern, das betreffende Organ gestreckten Verlaufes unter allmähliger Verjüngung nach unten bin durchzieht, um erst in dem Winkel zwischen $Z$ werchfell und Wirbelsăule unweit der Oberfläche zu enden. An diesen Punkt ist also das untere Lungenende zu verlegen."

Diesen Bronchus, der wie eine Axe jede Lunge durchläuft, nennt A eby "Stammhronchus".

Die Verzweigung dieser ist "streng monopodisch: Gleiches gilt für die weitere Verzweigung ihrer Seitenäste. Abweichungen von dem strengen Gesetze kommen im allgemeinen (!) erst in weiter vorgeschobenen Bezirken dadurch vor, dass der Gegensatz zwischen Stainm und Zweig sich verwischt, indem beide an Stärke einander gleich werden und so äusserlich das Gepräge gleichwerthiger Theilstücke eines gemeinschaftlichen Ganzen annehmen. In den Endverzweigungen dürfte dies wohl zur Regel werden, doch fehlen mir hierüber eigene Erfahrungen. - Die Annahme der Dichotomie findet anscheinend eine Stütze in dem Verhältniss zwischen dem Stamme der Luftröhre und ihren beiden Aesten. Solches ist indessen nicht der Fall. Dic Luftröhre ist eine selbständige Bildung, welche in unpaarer Grundlage den paarigen Bronchialbanm zusammenfasst.“

Aeby macht als Erster auf die Scheidung des Bronchialbaumes in einen eparteriellen und einen hyparteriellen Abschnitt aufmerksam.

Die primären Aeste des Stammbronchus nennt er Seitenbronchien. Sie sind theils ventrale, die doch eigentlich lateral verlaufen, theils dorsale, die wirklich dorsal verlaufen. Die ventralen und dorsalen alterniren in der Regel, doch nicht bei allen Species. Die Ursprünge der zwei Reihen liegen einander so nahe, dass nur ein ganz schmaler Streifen zwischen ihnen frei bleibt. Die Seitenbronchen bilden die Seiten eines Prisma, dessen scharfer Rand vom Stammbronchus g'ebildet wird.

Abwärts nehmen die Seitenbronchien an Grösse ab. „Dafür steigert sich ihre Neigung zur Abgabe von Seitenästen an den Stammbronchus. Die betreffenden Uebertragungen lassen sich häufig genug Schritt für Schritt auf das Deutlichste verfolgen. Sie geschehen immer nach innen hin, und dann überdeckt sich das vorber kable Gefilde des Stammbronchus mit dorsalen und ventralen Nebenbronchien, die, wo sie reichlich und kräftig vorhandez sind, mit ihrem üppigen Geäste die strengen Hauptlinien des Brouchialbaumes verschleiern und das Auge täuschen. Der sicher geschulte Blick wird sich durch sie nicht irre führen lassen. Ihrem Stammvater bleiben sie dicht zur Seite oder, und das ist der häufigere Fall, sie wandern nach abwärts."

Die Nebenbronchien zeigen ihren untergeordneten Rang durch 
Zur Entwickelung und Verzweigung des Bronchialbaumes etc. 611

ihre Unbeständigkeit an, indem sie einigen Thierspecies fohlen. Sehr selten löst sich ein Seitenbronchus in Nebenbronchien ganz auf, und so entsteht denn eine Lücke in der Reihe der Seitenbronchien. "Wohl aber verschwindet der anfängliche Grössenunterschied zwischen beiden Gruppen gegen das Ende des Bronchialbaumes hin immer mehr, bis zuletzt in dessen Wipfel cine Scheidung der typischen von den bloss accessorischen Bestandtheilen bisweilen mit Schwierigkeiten zu kämpfen hat. Diese sind es, die, wie schon früher angedeutet worden, das wirkliche Zahlenverhältniss der Seitenbronchien in Frage stellen können."

Das eparterielle System besteht immer aus nur einem einzelnen Bronchus, der ,ziemlich genau in einer Mittelstellung. ${ }^{\prime}$ zwischen den dorsalen und den ventralen $Z$ weigen entspringt, sich in diesen beiden Richtungen verästelt und verschmolzene eparterielle, ventrale und dorsale Zweige repräsentirt.

Was die symmetrische Divergenz der beiden Stammbronchien angeht, so ist das Verhältniss bei verschiedenen Thierarten verschieden. Nur bei wenigen Arten findet sich Symmetrie. Bei vier Arten bildet der eine Stammbronchus die direkte Fortsetzung der Trachea. In dor Regel, aber nicht immer, ist es der rechte Stammbronchus, der sich am meisten dieser Stellung nähert.

Die Seitenbronchien bilden gegen die Spitze des Stammbronchus stets spitzere Winkel mit diesem.

Der erste Seitenbronchus steigt, er sei ep- oder hyparteriell, inmer in die Lungenspitze hinauf.

Aeby meint, dass die Sonderstellung des eparteriellen Bronchus "sich in nichts so klar ausspricht", wie in dessen Neigung seinen Platz so zu wählen, dass er sich vom hyparteriellen System abhebt. Sein Abstand vom ersten hyparteriellen Aste ist entweder grösser oder geeringer als der Abstand zwischen den ersten hyparteriellen Aesten unter einander; nur bei wenigen Arten war das nicht der Fall.

Der Stammbronchus, der den eparteriellen Ast trägt, ist immer weiter als der andere.

Das bleibende Verdienst A e b y's liegt in seinen ausgedehnten und genauen, comparativen Untersuchungen über die Formen des Bronchialbaumes, die Lageverhältnisse der einzelnen Componenten, die Dimensionen n. s. w. Sein Buch bezeichnete eine Revolution in der Betrachtung der Lungen; aber wie so viele Reformatoren schlug er zu hart, traf zu weit, baute andererseits auch zuviel auf, indem ein Theil des Gebäudes auf schwachen Füssen zu stehen kam.

Wo war die Berechtigung der vielen harten Worte gegen die Dichotomie? War es ihre Schuld, dass man vor A eby sich nicht die Mïhe gegeben hatte, den Bronchialbaum genauer zu untersuchen?

Die Lehre von der Dichotomie der Bronchen war aus 
embryologischen Untersuchungen, die sie in so vielen Fällen klar und unzweideutig zu Tage treten liessen, wenn auch die Ergebnisse in anderen Fällen weniger eindeutig waren, hervorgegangen.

Die Anatomen, nicht die Dichotomie, die Gelehrten, nicht die Wissenschaft, trugen die Schuld, dass die Verbältnisse der erwachsenen Lunge nicht ordentlich untersucht worden waren.

Und war es rerkehrt, dass man die Dichotomie von den Verłältnissen beim Fötus ohne weiteres in die erwachsene Lunge tiberfuhrte, so war es ein nicht geringeres Wagniss, wenn A eby, trotz der errungenen embryologischen Erfahrungen, die Resultate seiner an der erwachsenen Lunge angestellten Untersuchungen in die fötale Lunge übertrug, ja so weit ging, dass er die Möglichkeit einer ungetheilten Lungenanlage bestritt, weil er meinte, in erwachsenen Lungen niemals anderen als monopodischen Vorgängen begegnet zu sein.

Und doch muss er zugeben, dass auf einem gewissen Punkte im Bronchialbaume die Dichotomieen unwiderleglich auftreten, ja, „in den Endverzweigungen dürfte dies wohl zur Regel worden - doch fehlen mir dariiber eigene Erfahrungen!"

Diese Dichotomie erklärt er - wie K ät $\operatorname{ta}$ e r - gauz willkülich dadurch weg, dass er ein besonders lebbaftes Wachsthum und eine ebensolche Verzweigung der Seitenäste annimmt. Ein Beweis dafür, dass so was wirklich stattgefunden habe, versucht er aber nicht zu führen. Wir werden später hierauf zurïckkommen.

Wie begründet A eby den so stark betonten Unterschied zwischen Seiten- und Nebenbronchien? Die Seitenbronchien, sagt er, verlaufen in zwei Richtungen, ventral (d. h. lateral) und dorsal. Von ihnen entspringen Nebenbronchen, die in andere Richtungen gehen. Abwärts am Stammbronchus sehen wir doch Aeste medial und wirklich ventral abgehen. Da diese sich nicht nach den - von A e b y geschriebenen - für die Seitenbronchen geltenden Gesetzen richten, müssen sie Nebenbronchen sein, „die an den Stammbronchus abgegeben worden sind". A e b y sagt wohl, dass man oft die betreffenden Uebertragungen genau verfolgen kann; er sagt aber nicht, wie man das sieht. Auch für $\mathrm{H}$ is scheint die Aeby'sche Lehre von den Nebenbronchien wenig überzengend gewesen zu sein, wenn er auch formell seinen Angriff auf den 
Bronchus cardiacus beschränkt. Meine Anschauungen über diese Frage werden weiterhin in meiner Arbeit Platz finden.

Wenn Aeby seine Behauptung, dass der Bronchus eparterialis anatomisch verschmolzene, ventrale und dorsale Aeste reprïisentire, dadurch stützt, dass jener ,ziemlich genau" eine Mittellstellung zwischen den zwei Reihen von hyparteriellen Aesten einnimmt, dann scheint dies nur eine schwache Stitze, da ja diese Aestereihen, wie er selbst lehrt, mit ihren Ursprüngen so dicht aneinander stehen, dass nur ein ganz schmaler Streifen zwischen ihnen frei bleibt. Ein so grosser Bronchus, wie der eparterielle, muss darum, wenn er überhaupt in derselben Gegend der Peripherie des Stammbronchus wie die hyparteriellen liegen soll, eine Mittelstellung zwischen den zwei Reihen einnehmen. Etwas ganz anderes ist es ja, dass der eparterielle Bronchus physiologisch dorsalen und ventralen Aesten entspricht, indem er sich in diesen beiden Richtungen verästelt.

Die Frage hängt auf das genaueste mit der Hanptfrage - Dichotomie oder Monopodie? - zusammen und wird darum erst dann vollkommen beleuchtet worden können, wenn wir diese Streitfrage behandelt haben.

Die mit so grosser Bestimmtheit - „ein für allemal" von A eby behauptete Lehre vom Alleinherrschen der Monopodie blieb nicht lange unangefochten.

Schon 7 Jahre später folgte $\mathrm{His}$ der an die Embryologen gerichteten Aufforderung A ebys die Sache näher zu untersuchen, und er kam zu wesentlich anderen Resultaten.

His lehrt, dass die ursprünglich einfache Lungenanlage sich secundär theilt und so zwei Röhren bildet, deren Enden nach rückwärts wachsen.

Die Sprossenbildung beginnt beim Menschen am Schlusse des ersten Monats; nach Mitte des zweiten Monats ist der Bronchialbaum schon reich verzweigt.

„Meine eigenen bei früherem Anlasse publicirten Constructionsbilder menschlicher Embryonen zeigen auch ihrerseits den Stammbronchus als ein die mediale bezw. vordere Seite des Astgebietes einnehmendes Rohr, dem die übrigen Bronchen seitenständig angefïgt sind."

$\mathrm{H}$ is giebt Constructionshilder von einem ca. 4 Wochen alten menschlichen Embryo: "Als erste Spuren einer Gliederung zeigt der linke Lungensack zwei, der rechte drei knospenartige Auftreibungen. Davon bildet jederseits die "primäre" Endknospe das dorsalwärts um- 
gebogene, blinde Endstück des Epithelganges, während die übrigen von höher gelegenen Stellen desselben ihren Ursprung nehmen. ${ }^{*}$

Jederseits findet sich eine "Endknospe" und eine "Seitenknospe“, rechts dazu auch eine "Oberknospe“. Jede von diesen bildet die Grundlage für eine der 5 Abtheilungen des erwachsenen Bronchialbaumes. An der Stelle des linken Bronchus, die dem Sitze der Oberknospe der rechten Seite entspricht, fehlt eine solche.

"In charakteristischer Weise sind die Seitenknospen dem Stamm. bronchus etwas oberhalb der Stelle aufgesetzt, wo derselbe eine scharfe Knickung erfuhrt."

"Die weitere Ausbildung der epithelialen Lungenanlage erfolgt durch Auswachsen und durch zunehmende Gliederung der fünf primüren Knospen. Im Allgemeinen tritt bei den nachfolgenden Vergrösserungen des Gangsystems immer mehr ein Gegensatz zwischen cylindrisch sich formenden Wurzelröhren und aufoetriebenen Endabschnitten oder sekundären Knospen hervor. Die Röhren verlängern sich, und aus ihnen gehen, nachdem sie einmal angelegt sind, keine neuen Knospen hervor. Der Ausgangspunkt neuer Formgebilde sind die sekundären Endknospen. Diese verlieren ihre kugelige Anfangsform, indem sie an der der Anheftung gegenüberliegenden Stelle eine Abplattung erfahren. Es leitet sich dadurch eine Zweischeidung ein, die bald darauf in schärferer Weise sich ausprägt. Derselbe dichotomische Spaltungsmodus wiederholt sich durch spätere Stufen hindurch in ahnlicher Weise, bis schliesslich bei Bildung der Alveolargänge das Hervortreten seitenständiger Knospen wieder zur Geltung gelangt. Während ich in Betreff des Stammbronchus und seiner monopodischen Verzweigung mich völlig an $\mathrm{Aeby}$ anschliesse, bin ich im Fall, für die Seitenbronchen einen ausgeprägten dichotomischen Verzweigungsmodus zu vertreten."

$\mathrm{H}$ is giebt danach Constructionsbilder von einem $8,5 \mathrm{~mm}$ langen Meuschenembryo. Er bemerkt darüber unter anderem: "Dem kriftig entwickelten Mittelgeschoss gegenüber erscheint das Untergeschoss noch sehr im Rückstande. Wohl sind auch hier schon Anlagen von Seiteubronchen gegeben, dieselben sind indessen nur in Gestalt von kurz oder gar nicht gestielten Knospen vorhanden."

A e by hat Recht, indem. er den eparteriellen Bronchus als dorsoventral beschreibt und ihn als einen den ersten und zweiten $Z$ weigen entsprechenden Ast auffasst. Ende des zweiten Monats ist der Unterschied zwischen der rechten und der linken Seite im wesentlichen nur der, dass dort die Astgebiete des oberen und des mittleren Lappens jedes für sich entspringen, während sie hier auf einem gemeinsamen Stiele sitzen.

Jetzt folgen bei $\mathrm{H}$ is Constructionsbilder eines $10,5 \mathrm{~mm}$ langen Embryo: „Das untere Endstück der Anlage läuft in einige breit gestielte Knospen aus, deren Deutung nicht absolut sicher zu geben ist. Mir scheint, dass der zweite dorsale und der dritte ventrale Bronchus 
sich bereits abheben, und dass der dazwischenliegende Stumpf als Eade des Stammbronchus zu deuten ist."

His kann Ae by nicht beipflichten, indem dieser den Bronchus cardiacus als einen Nebenbronchus bezeichnet: "Mag man die Constructionsbilder oder mag man die Durchschnitte selber betrachten, so stellt sich der Bronchus cardiacus stets als Bildung eigener Art heraus." $\mathrm{Er}$ ist der einzige Seitenbronchus, der wirklich ventrale Richtung hat. Für seine Selbständigkeit spricht weiter sein frühes Auftreten und der weite Abstand, der ihn sowohl vom ersten wie vom zweiten ventralen Bronchus scheidet. Er ist ein echter Seitenbronchns, der das Schema bricht ${ }^{1}$ ).

Die linke Lunge entwickelt sich etwas schneller als die rechte. Die Seitenbronchen sind links weiter entwickelt als die entsprechenden rechts. Der erste ventrale Ast entsencet extra einen dorsalen Ast, der in das Obergeschoss emporsteigt und dem rechten eparteriellen Bronchus entspricht.

Alle Seitenbronchen entspringen links ein wenig höher am Stammbronchus als die entsprechenden rechts.

Ueber die weitere Entwickelung sagt His: "Mit zunehmender Entwickelung werden die Formen des Bronchialbaumes immer schlanker, ein System von cylindrischen Röhren schiebt sieh in wachsender Ausdehnung zwischen die aufgetriebenen Endknospen und den Stammbronchus ein. An keiner Stelle findet sich eine Andeutung, als ob aus den einmal cylindrisch gewordenen Wurzelröhren Seitensprossen zn entstehen vermöchten. Die einzige Productionsstätte neuer Formbestandtheile sind die Endknospen, und zwar erfolgt die Umgestaltung auf dem Wege dichotomischer Theilung. Die Knospen verlieren ihre kugelige Grundform, indem sie an der der Anheftung g'egenüberliegenden Seite sich abplatten und zugleich in transversalem Sinne strecken. Bald tritt eine trennende Furche auf, wodurch die ursprünglich einfache Knospe in zwei getrennte Vorwölbungen auseinander geht. Allmählich emancipiren sich diese letzteren und bekommen auch ihrerseits cylindrische Stiele, worauthin derselbe Vorgang von Neuem Platz greifen kann. Der Winkel, unter dem zwei neu entstandene Knospen divergiren, ist kurz nach ihrer Entstehung am grössten. Mit zunehmender Verlängerung der Stiele wird der Divergenzwinkel im Allgemeinen geringer." ${ }^{2}$ ).

„Insofern das untere Ende des Stammbronchus auch seinerseits nach Art einer Endknospe weiter wächst, kann für die unteren Bezirke

1) Würe das nicht ein Fehler des Schemas? Verf.

2) Dieser letzte Punkt zeigt, dass His nahe daran war, die sympodiale Verschiebung der Tochteräste zu finden (siehe später). Nur hat er nicht gesehen, dass die Winkel unter dem späteren Wachsthume nicht nur spitzer werden, sondern auch die Lage ihrer Theilungsaze und ihrer Winkelschenkel ändern. 
(vom dritten hyparteriellen Seitenbronchus aus nach abwärts) das Prinzip einer monopodischen Verzweigung nicht aufrecht erhalten werden, wie denn auch zuletzt der Stammbronchus keineswegs scharf von den Seitenbronchen unterscheidbar bleibt ${ }^{\mu}{ }^{1}$ ).

"In der tiefgreifenden Weise, wie dies Aeby thut, darf man, glaube ich, die Vorgänge monopodischer und dichotomischer Sprossenbildung überhaupt nicht zu einander in Gegensatz stellen “2).

Nachdem sich eine Zeit lang dichotomische Processe abgespielt haben, "tritt aber ein Zeitpunkt ein, wo die Endknospen aufhören sich dichotomisch zu theilen, und wo sie wieder in ein System melır oder minder ausgiebiger Seitenknospen auslaufen. Die spätere Geschichte des Bronchialbaumes habe ich bis jetzt kcine Gelegenheit gefunden, zu studiren. Zwei Punkte scheinen mir dabei beachtenswerth: Einmal ist die Möglichkeit gegeben, dass die bei zunebmender Entwickelung des Bronchialbaumes eintretende Raumbeschränkung ein weiteres Längenwachsthum gestreckter Röhren hemmt, und dass Aenderungen im Verhalten der sich ausdehnenden Endknospen dadurch bedingt werten. Sodann aber ist ein bonderes Augenmerk auf die Muskelanlagen zu richten. Die cylindrischen Bronchialisste sind schon sehr frühzeitig von circulären Muskelzellen umgeben, und wie mir scheint, darf man deren Bedeutung für die Beibehaltung regelmässiger, cylindrischer Form keineswegs unterschätzen. Die Bildungsstätte der Alveolargänge und der Lungenbläschen fällt in ein Gebiet, in dem die Muskeln keine Rolle mehr spielen, und das daher einer freieren Gestaltung des epithelialen Hohlkörpers Raum bietet."

Noch 6 Jahre nachdem $H$ His die vorstehenden Untersuchungen und Resultate veröffentlicht hatte, schliesst sich Miller wieder an Aeby an, indem er jede Dichotomie verneint und sagt: "I have thus far been unable to discover any regularity in their (s. die Bronchial. röhrchen) distribution."

Bevor ich mich jetzt zu meinen eigenen Untersuchungen uber den besagten Gegenstand wende, werde ich erst einige Mit-

1) Die Monopodie gilt also nur für die Bildung des eparteriellen und der zwei ersten hyparteriellen Seitenbronchen. Nach His wird also der Bronchialbaum folgendermaassen gebildet: 1. Die einfache Lungenanlage theilt sich dichotomisch. 2. Jeder der so gebildeten zwei Bronchen wird zu einem Stammbronchus, der monopodisch rechts drei, links zwei Aeste a bgiebt. 3. Alle späteren, unzählbaren Verzweigungen des Bronchialbaumes geschehen dichotomisch. 4. Die Alveolen werden monopodisch gebildet.

2) Man sieht, wie His hier Punkt für Punkt das Systen Aeby's angreift und, ohne es ganz umstürzen zu wollen, ibm die Consequenz, dureh welche der Urheber, bisweilen freilich etwas künstlich, es zu stützen versucht hatte, entnimmt. 
theilungen über die von mir verwendete Technik geben müssen. Die Behandlung der Präparate von embryonalen Lungen war immer: Fixation mittelst Formol - M ü ll e r's Flüssigkeit $(1-10)$, Färbung mit Alauncochenille oder Hämatoxylin, Einbetten in Paraffin, Canadabalsam. Erwachsene Lungen wurden entweder ebenso behandelt oder mit einer $2 \%$ Silbernitratlösung durch die Bronchen injicirt.

Als geeignete Methoden hatte ich mir von vornherein die Corrosions- und Reconstructionsmethoden vorgestellt, und ich babe beide in sehr ausgedehnter Weise versucht. Die Corrosion von Injectionen der Lipowit'schen Legirung, die anscheinend sehr schöne Resultate ergab, hat sich mir aber als sehr unznverlässig erwiesen, indem die allerfeinsten Zweige der Alveolensysteme nicht oder nur ausnahmsweise injicirt, die verschiedenen Astgebiete unregelmüssig, einige gar nicht gefullt und endlich die räumlichen Verhältnisse sehr stark modificirt werden.

Die historisch interessante und für eine vorläufige Orientirung sehr geeignete $\mathrm{R}$ eisse is s en'sche Methode ist aus ungefähr denselben Gründen für ein genaueres Detailstudium nicht verwendbar.

Als die schönste von allen bisherigen plastischen Methoden steht die B orn'sehe Methode da.

Ich habe sie in der Strasser'schen Modification verwendet, indem ich die Schnitte auf Schreibpapier gezeichnet und dann die Papierblätter auf die Wachsplatten geklebt habe.

Die im Handel zu habenden, sehr ungenauen Wachsplatten habe ich nach der auch von $S$ trasser angegebenen Walzenmethode geregelt, nur durch ein einfacheres und billigeres Instrumentarium.

Ich lasse, wie Strasser, einige Messinglineale von der Dicke, die ich meinen Platten zu geben wïnsche, von einem Instrumentenmacher verfertigen. In einen tiefen Papprabmen lege ich eine dicke Platte aus Spiegelglas. Hierüber wird ein Stïck glattes Pergament oder ein Stuck Carton, reichlich mit Oel imbibirt, gelegt, dann kommen zwei einander entsprechende Messinglinale, zwischen welchen eine Wachsplatte, ein wenig dicker als die zu machende, und auf diese wird endlich die Zeichnung gelegt. Das ganze (d. h. Lineale und Zeichnung) wird mit einem Stück Pergamentpier oder geölten Carton bedeckt, und jetzt drücke 
man kräftig und andauernd mit einem heissen Plätteisen, bis das Wachs weich wird und dem Drucke nachgiebt, so dass das Eisen leicht und glatt auf den mit dem Papier bedeckten Linealen gleitet. Nach Behandlung jeder Platte wird das Eisen anf eine mittelst einer Spirituslampe geheizte Pfanne oder auf den heissen Ofen gestellt. In dieser Weise verschafft man sich leicht und billig Platten von beliebiger und genauer Dicke.

Auch nicht die Plattenmodellirmethode war es aber, die mich zum Ziele führte. Neben ihren schönen Eigenschaften baften ibr auch gewisse Mängel an. Weit besser als irgend eine frïhere Methode giebt sie die räumliche Form des Gegenstandes wieder, und die Leichtigkeit, mit der diese der direkten Anschauung zugänglich wird, macht die Methode unübertrefflich für Demonstrationszwecke.

Andererseits ist sie, wo von grösseren Serien und von complicirteren Gegenständen die Rede ist, eine ausserordentlich lang. wierige und mühselige Methode, und dazu ist sie für feinere Dctails nicht genau. Sie basirt auf 4 Manipulationen, die jede für sich Febler einführen müssen:

1. das Zeichnen des Schnittes,

2. das Ausschneiden der Wachsplatte,

3. das Aufeinanderlegen der Platten und

4. die Zusammenklebung der Platten.

Von diesen 4 Punkten ist Punkt 1 fast gar nicht, Punkt 3 nur wenig schädlich.

Bei der Reconstruction solcher grösseren Gegenstände, wie zum Beispiel des Herzens des Embryo oder der Pyramiden der Niere werden auch das Ausschneiden und die Zusammenklebung der Wachsplatten keinen grösseren Schwierigkeiten begegnen. Hierbei kommt wesentlich nur der Fleiss in Frage, und die Genauigkeit des Resultates wird eine vollständig gentigende werden können. Wo es sich aber um solche kleine und complicirte Gegenstände wie die kleinsten Bronchien des Fötus oder die Alveolen des erwachsenen Thieres handelt, ist die Sachlage eine andere.

Die allerfeinsten Details darzustellen ist überhanpt unmöglich. Um die schmalen Wachsstreifen wegschneiden zu können, die zum Beispiel den interalveolären Septa und dergleichen entsprechen, muss man sehr starke Vergrösserungen verwenden; hierdurch werden aber die Gesichtsfelder sehr klein, und die Arbeit wird 
unausführbar. Und selbst recht grobe Formverhältnisse werden auf diese Weise sehr ungenïgend wiedergegeben. So vergleiche man das Bild Millers von einer seiner Reconstructionen mit seiner Zeichnung eines Schnittes durch die verschiedenen Cavitäten des Alveolensystems, und man wird sehen, ein wie diirftiges Verstïndniss man von diesen und von deren gegenseitigem Verhältniss durch Betrachtung der Reconstruction erhält, wie gering eigentlich das Resultat der grossen Arbeit ist.

Die folgende - soviel ich weiss, nicht früher benutzte Methode scheint mir in ihrer relativen Schnelligkeit und beinahe absoluten Genauigkeit recht grosse Vorritge zu besitzen.

Das Princip ist dies, alle Schnitte einer Serie in Form von vergrösserten Zeichnungen in der richtigen, gegenseitigen Lage so zu fixiren, dass man schnell und leicht die einzelnen Zeichnungen vergleichen, die Form- und Lageveräinderung eines jeden Hohlkörpers verfolgen und kleine Aenderungen in diesen Hinsichten geuau messen kann:

Ich zeicbne alle Schnitte einer Serie auf Schreibpapier, das zwar nicht durchsichtig ist aber doch so diinu, dass man durch ein Blatt deutlich die Zeichnung auf einem anderen sehen kann, wenn beide zusammen vor clas Licht gehalten werden. Grössere Darchsichtigkeit ist nicht nur unnöthig, sondern nicht erwünscht. Mit der untersten Zeichnung anfangend, befestige ich das eine Ende dieser mit zwei Reissstiften anf eine dicke Pappplatte, hebe den freien Theil der Zeichnung von der Unterlage empor, halte ihn mit der folgenden Zeichnung zusammen gegen das Licht, bringe die einzelnen einander entsprechenden Contouren (ler zwei Zeichnungen zur möglichst vollständigen Deckung, lege wieder die zwei Blätter, von denen das eine noch frei, das andere an der Unterlage befestigt ist, glatt nieder, und während ich sie stets mit zwei Fingern in ihrer jetzt gefundenen, richtigen gegenseitigen Lage halte, entferne ich die zwei Reissstifte und bohre sie danach durch beide Blätter hindurch. Darauf wird die nächste Zeichnung auf dieselbe Weise zugefugt u. s. w., bis die ganze Serie zusammengeheftet ist; sie wird dann regelmässig rectangulär beschnitten.

Die zwei früher genannten Fehlerquellen, die wesentlich die Ungenauigkeit der Reconstructionsmethode bedingen, werden 
wie ersichtlich, hier vollständig umgangen. Das Zeichnen und das Zusammenlegen der Zeichnungen können mit geradezu beliebig grosser Genauigkeit vorgenommen werden.

Indem man ein so hergestelltes "Billerbuch" in beiden Ricbtungen durchblättert, kann man alle Verzweignngen eines Bronchiolus verfolgen, genau dic Form und Grösse der einzelnen Hohlräume und die gegenseitigen Verbältnisse dieser untersuchen. Es liegt in der Methode keine Begrenzung der Ausdehnung, die man seinen Untersuchungen geben kann. Nimmt man die Dicke der Schnitte genügend klein, die Vergrösserung der Zeichnungen genügend gross - und sie braucht hier nicht so gross wie bei der B orn'schen Methode zu sein, indem dünne Septa und dergleichen hier nicht zu modelliren, sondern nur zu zeichnen sind; - und zeichnet man mit Genauigkeit, so lässt sich auch das kleinste Detail in dieser Weise darstellen.

Weiter kann man alle möglichen Messungen mit der grössten Genauigkeit vornehmen, nicht nur die von Linien und Winkeln im Papierplane, sondern auch von solchen, die in allen anderen Plänen liegen. Eine jede Linie lässt sich entweder direkt messen oder mittelst des Pythagoräischen Satzes berechnen. Winkel, die im Plane der Zeichnung liegen, werden direkt mit Gradbngen oder genauer trigonometrisch mittelst folgender Formelund Logarithmentabelle gefunden:

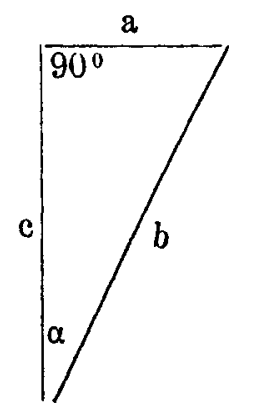

$$
\begin{aligned}
& \sin \alpha=\frac{a}{b}, \\
& \cos \alpha=\frac{c}{b}, \\
& \operatorname{tg} \alpha=\frac{a}{c}, \\
& \cot \alpha=\frac{c}{a} .
\end{aligned}
$$

In derselben Weise werden die in den das Papier rechtwinkelig schneidenden Plänen liegenden Winkel berechnet, wie aus der beigefügten Zeichnung erbellen wird.

Mit einer Nadel sticht man durch die Zeichnungen hindurch und projicirt in der Weise die Punkte $A$ und B auf den Schnitt, der eben die Winkelspitze der divergirenden Bronchialzweige a 
und b aufnimmt. Die Grössen 9 and 41 werden auf diesem Schnitte einfach durch Centimetermaass ermittelt. War die Vergrössernung der Zeichnungen zum Beispiel 1: 100, hätten wir den Winkel so bestimmt: $\operatorname{tg} \alpha+\operatorname{tg} B=\frac{15}{y}+\frac{1}{4} \frac{6}{1}$, woraus die Grösse leicht durch Logarithmenberechnung und tabelle $z u$ finden ist.

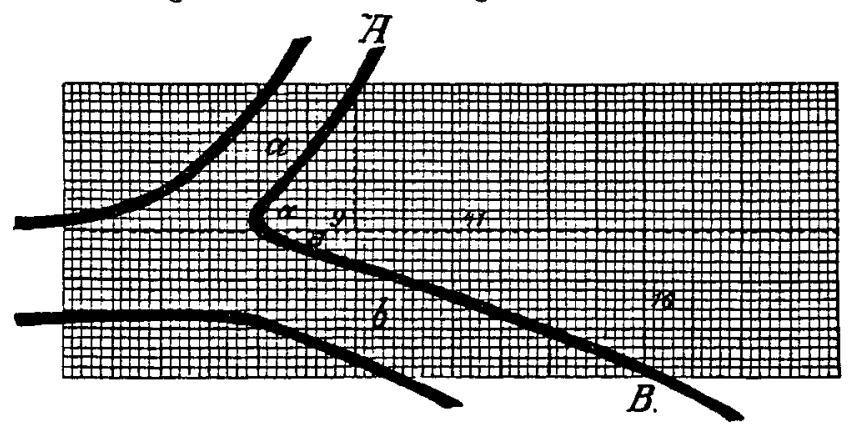

Winkel, die den schräg daș Papier schneidenden Plänen zugehören, werden durch eine wenig complicirtere Berechnung. gefunden, indem man zuerst den Pythagoräischen Satz und danach die oben angeführten trigonometriscben Formeln verwenden muss.

Das Volum aller möglichen Hohlkörper lässt sich recht genau berechnen, indem man sie als Cylinder, Kugel und Sphäroide betrachtet und ihre Diameter in die tolgenden Formeln substituirt :

$$
\mathrm{V}_{\mathrm{c}}=\pi \mathrm{r}^{2} \mathrm{~h} ; \mathrm{V}_{\mathrm{k}}=\frac{4}{3} \mathrm{r}^{3} \pi ; \mathrm{V}_{\mathrm{s}}=\frac{4}{3} \pi \mathrm{abc} .
$$

Der grösste Vortheil dieser Methode liegt darin, dass man durch sie seine Untersuchungen weit mehr ausdehnen kann, als es durch die Reconstructionsmethode möglich ist. Ich habe für die hier mitzutheilenden Studien etwas mehr als 1200 Zeichnungen nach meinen im Ganzen mehr als 10000 Schnitte enthaltenden Serien verfertigt. Ein entsprechendes Material nach Born zu reconstruiren wäre selbstverständlich unmöglich gewesen.

Die allerfrühesten Stadien der Entwickelung der Lungen selber zu untersuchen, habe ich keine Gelegenheit gehabt, weil ich mir so junge Embryonen nicht habe verschaffen können. Das früheste Stadium, das mir in die Hände gekommen ist, hat eine Länge von $7 \mathrm{~cm}^{1}$ ). Ich habe weiter die Lungen von 16,26 ,

1) Hier, wie überall, wo nicht anders ausdrücklich betont wird, 
44, 60, 80, 90 und $102 \mathrm{~cm}$ langen Rindsembryonen untersucht, weiter die von 2 Tage, $21 / 2$ Monat und 11/2 Jahre alten Ochsen. Ueberall habe ich die unzweifelhafteste Dichotomie gefunden.

Es muss scharf hervorgehohen werden, dass Worte wie Verzweigungsmodus, Dichotomie, Monopodie a. a. als Bezeichnungen theils für einen Process, eine Entwickelung, theils für das durch diesen Process hergestellte Resultat verwendet werden können, und in der That hat man früher viclfach diese zwei Begriffsreilen vermischt.

A eby untersuchte und beschrieb das fertige Resultat, wie es in der erwachsenen Lunge vorliegt. Er fand uiberall ant den grösseren Bronchien monopodisch angebrachte Zweige, und er erlaubte sich zu schliessen, dass sie auch monopodisch entsprungen seien. In den kleinsten Bronchien ändert sich nim Allgemeinen" anscheinend dieses Verhältniss, ja, in den alleräussersten Endverzweigungen, die er freilich nicht selbst untersucht hat, seien die dichotomischen Processe anscheinend die herrschenden. Der Grund, dass die Monopodie hier eine Dichotomie vortätsclit, ist nach Aeby - wie nach K ilttner - der, dass die Seitenzweige schneller und reicher als der Hauptstamm wachsen und sich verzweigen, wodurch der Schein entsteht, als ob die zwei Astgebiete von demselben Alter und derselben Ordnung seien. Acby, der selber die Entwickelung nicht untersucht hat, mag dies als eimen nicht ganz unnatturlichen Gedanken angesehen haben; im Munde Küttners lautet der Ausspruch aber sehr merkwtirdig. Hat er ja doch verschiedene Stadien der Entwickelung nntersucht. Er selbst erwähnt ausdritcklich das eines 50-60 Stunden alten Hühnerembryo, Rindsembryonen von $1,5,6-7,7-8 \mathrm{~cm}$ Länge; er sagt, dass die Verhältnisse von hier ab unverändert bleiben, bis der Embryo eine Länge von $38 \mathrm{~cm}$ erreicht hat, dass die Verzweigung stets in Form einer Theilung der kolbenförmigen Enden geschieht; endlich hat er auch postembryonale Stadien untersucht - und obwohl er also gesehen hat, dass immer eine dichotomische Endtheilung vor sich geht, lässt er sich dadurch irre leiten, dass die etwas älteren Verzweigungen ein handelt es sich um Rinderembryonen. Die Lünge wird von der Nasenspitze bis zur Schwanzwurzel gerechnet. 
monopodisches Aussehen darbieten, und durch eine etwas künstliche Erklärung verwandelt $\mathrm{cr}$ die Spitzendichotomie in eine maskirte Monopodie.

Die Endbronchien eines Embryonalstadiums sollten also, anders ansgedrückt, ehen in der Spitze (!) eine Seitensprosse entsenden, die aber schneller als der Mutterstamm wächst, wodurch beirle das Aussehen zweier gleichwerthiger Schwesterzweige annehmen ${ }^{1}$ ); bald aber giebt, wie die spätere Entwickelung zeigt, der Seitenspross den Kampf auf, während der Mutterbronchus siegreich weiter wächst - und die Monopodie ist wieder hergestellt. Um seine Darstellung zn behaupten, muss $\mathrm{K}$ iu $\mathrm{t} t \mathrm{n}$ er ein unbegründetes und unbegriindbares Postulat nach dem anderen einfülıren. Er bat seine Resultate theils durch Untersuchung von Sehnitten, theils durch Injection einer Mischung von Wachs, Canadabalsam und Zinnober erreicht.

Dass Miller sich $\mathrm{A} \mathrm{eby}$ angeschlossen hat, ist einfach dadurch zn erklären, dass er, wie dieser, beinahe nur erwachsene Lungen untersucht hat.

$\mathrm{H}$ is ist der Frage mit umfassenden embryologischen Untersuchungen näher getreten. $\mathrm{Er}$ hat anf allen Stadien, mit Ausnahme von den allerfrubestem in den Spitzen dichotomische Theilungen gefunden, und er hat denn auch keinen Augenblick gezögert, den Verzweigungsprocess als einen dichotomischen anzusprechen. Andererseits hat er keinen Versuch gemacht zu erklären, warum denn die Betrachtung der älteren Theile des Bronchialbaumes, ante sowohl wie post partum, so entschieden für die Monopodie zu sprechen scheint. Dieses Factum, das doch einer Erklärung bedürftig ist, dass andere Forscher zu dem Resultate ,eine konsequenten Monopodie" baben kommen können,

1) Warum wächst sie schneller? Und selbst dies angenommen, so ist hierdurch der Vorgang gar nicht erklärt. Man findet nämlich immer die äussersten Enden seitwärts divergirend und zwar ganz gleichmïssig zu jeder Seite der Verlängerung der Mutterachse. Warum wächst denn der Mutterzweig plötzlich nach der einen Seite, wenn er einen Zweig nach der andeern Seite abgiebt? Und wie kommt es, dass wir, wenn die Entwickelung ein wenig weiter vorgeschritten ist, den Mutterstamm direkt in seiner eigenen Verlängerung fortwachsen sehen, währeud er früher Winkel bildete? 
hat er vollständig nnberücksichtigt gelassen. Für die allerersten Stadien, Stammbronchus bis zum dritten, hyparteriellen Ast, lässt er die Anschaunngen A e by's über die monopodische Bildung der Seitenzweige bestehen - hier findet also noch die Monopodie einen letzten Zufluchtsort.

Der jüngst von mir untersuchte Rindsembryo ist, wie schon gesagt, $7 \mathrm{~cm}$ lang. Die rechte und die linke Lunge haben eine Länge von 11, beziehungsweise $8 \mathrm{~cm}$. Die Lappen sind deutlich angegeben. Der Bronchialbaum ist schon wohl entwickelt, in den grösseren Bronchien sind Längsfalten der Mucosa. Die Verzweigung betreffend, da findet sich schon jetzt ein wohl ausgesprochener Unterschied zwischen den seitenständigen Aesten der etwas grösseren Stämme und den endständigen der Endbronchien. Man sieht in einem Schnitte öfters die grösseren Zweige auf weiten Strecken von gan\% geradem Verlaufe, und von ihnen wie von einem Achsenstamme ansstrahlend sieht man mit wechselnden Zwischenräumen Aeste abgehen, die in Stärke dem Mutteraste nahe kommen und von einem dem ihrigen entsprechenden Bauc sind. Geht man aber etwas weiter peripherisch in die äussersten Endverzweigungen hinaus, dann findet man, dass der Achsenstamm nicht mehr seinen Verlauf direkt und ungestört fortsetzt. Verlïngert man das Stilck von ihm, das eben central vor Abgang eines Seitenastes liegt, dann fällt diese Verlängerung in den Zwischenraum zwischen Fortsetzung des Stammes und den Seitenast, jenem näher, mit ihm einen spitzen Winkel bildend, diesem entfernter, mit ilmm einen weniger spitzen Winkel bildend.

Bei einer noch mehr peripher gelegenen Generation theilt die Verlängerung der Achse den Zwischenraum zwischen Seitenast und Mutterstammfortsetzung etwas mehr gleichmässig, und so geht es weiter, bis die Achsenverlängerung der allerletzten Endtheilung den Zwischenraum zwischen den zwei Endästen ganz gleichmässig theilt. Je mehr wir uns von den centralen Theilen des Bronchialbaumes gegen die peripherischen Regionen desselben bewegen, um so mehr ausgesprochen zeichnet sich ein Uebergang der Monopodie in die Dichotomie, der Assymmetrie in die Symmetrie. Absolut regelmässig und stufenweise geschieht dieser Uebergang doch nicht. Es passirt, dass man an einer Stelle, wo die Monopodie und Assymmetrie anders ganz unangefochten herrschen, plötzlich einer ganz 
symmetrischen Dichotomie begegnet - ein typisches, obwohl nicht bei allen Arten sich findendes Exempel giebt die allererste Dichotomie, die Bifurcatur, die fast immer ein dichotomisches Aussehen, in einzelnen Fällen auch vollständige Symmetrie während des ganzen Lebens beibehalten (in den Raumverbältnissen begründet!) - wonach wieder mehrere monopodisch abgehende Zweige sich einstellen, bis der langsame, stufenweise sich vollziehende Uebergang in die symmetrischen Theilungen anfängt. Das umgekehrte Verhalten, eine Monopodie in den peripherischen, dichotomischsymmetrischen Gebieten, kommt dagegen niemals vor, wie das denn auch in der jetzt eben zu gebenden Erklärung der Sachlage natürlich und selbstverständlich begründet ist.

Ganz demselben Totalbild des Bronchialbaumes begegnen wir nun auf allen folgenden Stufen; ja auch die erwachsene Lunge ist nach demselhen Schema gebaut. Die Lunge wächst, und der Bronchialbaum rerzweigt sich immer reicher. Eine neue Generation entsteht nach der anderen, aber das Verhältniss bleibt stets dasselbe. Die äusserste Verzweigung ist dichotomisch und symmetrisch, nach einer gewissen Zahl von Generationen schwindet die Symmetrie, bis wir das ausgesprochene Bild eines Stammes haben, von dem laterale Zweige monopodisch entspringen.

Schon die Untersuchung einiger wenigen Stadien zeigt nun unzweifelhaft, dass die Zweige, die anf einem jüngeren Stadium dichotomische waren, später in monopodische umgestaltet worden sind. Diesen Vorgang könnte man sich so vorstellen, dass die Achse zwischen die endständigen dichotomischen $Z$ weige sich weiter verlängerte; theils sieht man aber niemals, ouch nicht andeutungsweise, so etwas, theils wïrde daraus eine Achse resultieren, deren Zweige je zwei einander gegenüber gestellt wären; die Aeste sitzen aber immer jeder für sich. Auch sieht man, wie schon $H$ is sagt, niemals, dass ein Seitenzweig sich an der Seite eines schon ausgebildeten Stammes zu bilden anfängt. Stied a meint freilich so etwas gesehen $z u$ haben und zeichnet eine kleine Vorbuchtung eines Bronchialrohrs, welche er als den ersten Beginn eines hervorsprossenden Seitenzweiges ansieht, hat aber dies sicherlich falsch aufgefasst. Niemand hat später angegeben, etwas ähnliches gesehen zu haben.

Wie in so vielen anderen Fällen zeigt auch hier das ein- 
zelne Stadium der Lungenentwickelıng an verschiedenen Stellen die Stufen, die jeder einzelne Zweig nach und nach durchgemacht hat. Man vergleiche die verschiedenen Verzweigungen desselben grösseren Astes oder solche in Lungen verschieden hoher Entwickelung; das Resultat wird immer dasselbe sein:

Der Ver\%weigungsmodus ist dichotomisch. Das leicht kolbenförmig erweiterte Bronchialende flacht sich am Fundus $a b$, theilt sich in zwei seitlich abgehende Blasen - "wäehst mit zwei Scheitelpunkten ${ }^{\prime}$ (Kit tner) - aus denen neue deste sich bilden, die danach sich wieder dichotomisch theilen werden. Dann ist jedoch schon eine Abänderung der Stellang der zwei älteren Zweige eingeleitet worden; der eine hat den anderen verdrängt, wird etwas weiter als dieser, bildet mehr und mehr die gerade Fortsetzung des Mutterstammes und sehicht darunter den Sehwesterzweig mehr und mehr zur Scite, wodurch dieser anscheinend in einen Seitenast monopodischen Ursprunges reducirt wird. Dieser Vorgang findet in der ganzen Wacbsthumsperiode der Lunge statt, und in dieser Weise wird nach und nach in jeder Lunge ein Stammbronchus, Glied um Glied durch einander folgende Dichotomieen gebildet; von diesem entspringen die bekannten ep- und hyparteriellen Seitenbronchien, und jetzt folgen stufenweise stets kleinere Zweige peripherwärts, die immer Seitenzweige einer Achse nächst höhcrer Ordnung, selbst aber auch Achsen der Aeste nëchst niedrigerer Ordnung sind, bis wir endlich ganz in der Peripherie die Dichotomieen mehr und mehr angedeutet, schliesslich in ihrer reinen Symmetrie wohl erhalten finden.

Das Gesetz des Verzweigungsmodus ist folgendes: konsequente I)ichotomie, die durch ungleiches Wachsthum der Schwesterzweige sowie durch successive Verschiebungen der Theilungsachsen das Aussehen der Monopodie annimmt ${ }^{1}$ ).

Am schönsten tritt dieses Gesetz in den Alveolensystemen der erwachsenen Lunge hervor, und hier war es auch, wo ich

1) Diese Art des Wachsthumes ist in der Botanik wohlbekannt und wird hier als Sympodie bezeichnet. Die Sympodie, die jetzt beschriebene Richtungsänderung eines ursprïnglich seitwirts abgehenden Zweiges der in die Stammesverlangerung hineinwächst, findet sich da sowohl auf dichotomischer wie auf monopodischer Basis. 
es erstmals erkannte. Hier geht der Terminalbronchus in Systeme ganz bestimmter Form, mit einer ganz bestimmten Anzahl Generationen, die man auf den verschiedenen Stadien wiedererkennen und vergleichen kann, iber. Bei der Beschreibung dieser Systeme werde ich diese Verhältnisse genauer besprechen.

Vorläufig werden wir jetzt noch einen Blick auf die allerfrühesten Stadien der Lunge werfen. Wie früher schon gesagt, bin ich mit A e by in der Betrachtung einverstanden, dass ein Organ, das in den 99 Hunderttheilen seiner Wachsthumsperiode thatsïchlich nach einem gewissen Gesetze sich entwickelt, wahrscheinlich demselben Gesetze auch in dem übrigen Hundertheile folgt. $\mathrm{J}_{\mathfrak{i}}$, mit einer gewissen Modification möchte ich seine Worte zu den meinicren machen: Ein Organ, das in seinem ganzen, so ungemein consequenten Aufbau $\mathrm{n} \mathrm{ur}$ von Dichotomie weiss, wird wahrscheinlich auch einer solchen in seinen ersten, grundlegenden Vorgäingen huldigen und damit seinen späteren Charakter vorzeichnen.

Ist es jedoch nicht erwiesen, dass der Verzweigungsmodus des $\mathrm{Stammbronchus}$ ein monopodischer ist? Der einzige, der einen Versuch das zu beweisen gemacht hat, ist $\mathrm{H}$ is. Das Studium der $\mathrm{H}$ i s'schen Abhandlung "Zur Bildung:sgeschichte der Lungen beim menschlichen Embryo" hat bei mir die Ueberzeugung wachgerufen, dass $\mathrm{H}$ is, der ja wohl die consequenten Spitzendichotomieen der nur ein wenig entwickelten Embryonen beobachtet hat, der aber das Problem der scheinbaren Monopodie der etwas älteren Stämme gar nicht beachtet zu haben scheint, die Monopodie für die allerfrïhesten Stufen, wo man viele, unmittelbar einander folgende Entwicklungsstadien baben muss, um den Vorgang in allen seinen Phasen verfolgen zu können, als fest stehend angenommen hat.

Sehe ich jetzt, mit den Erfahrungen, die ich bei meinen Arbeiten mit dem Bronchialbaume der Rinderembryonen gemacht habe, auf die Zeichnungen, die $\mathrm{H}$ is nach seinen Constructionen giebt, dann bin ich so weit davon entfernt sehen zl können, dass sie die Monopodie des Stammbronchus beweisen, dass sie mir im Gegentheile eher dafür zu sprechen scheinen, dass die Verzweigung hier ganz ebenso, von denselben sympodischen Vorgängen begleitet wie auf allen folgenden Altersstufen, vor sich gehen. 
Solche planen Bilder eines räumlich ausgedehnten Astsystems geben selbstverständlich einen sehr dürftigen Begriff von demselben. Viele Aeste, die dem Betrachtenden entgegenstreben, werden in starker optischer Verkürzung gesehen, bekommen vielleicht das Aussehen kleiner, sitzender Knospen, während sie thatsïchlich von recht langen Armen getragen werden. Andere, die schief dem Auge verlaufen, werden ebenfalls verkürøt; die Grösse der Winkel, das symmetrische oder asymmetrische Verhältniss der Zweige ihrer Mutterachse gegenüber - viele solche, sehr wichtigen Details werden in solcher Darstellung modificirt oder verschwinden gänzlich. Es sind also nur verhältnissmässig wenige Aeste, die dem Beschauer so glücklich sich zeigen, dass man über diese Verhäjtnisse klar werden kann.

Gründliche, combinirte Betrachtung der Profil- und en face-Bilder, die $\mathrm{H}$ is gegeben hat, hilft doch in den meisten Fällen uber alle Schwierigkeiten hinweg, und es ist nach einer solchen genamen Untersuchung, dass ich die Ueberzeugung gewonnen habe, dass, wenn $\mathrm{H}$ is nur mehrere Stadien vor dem 4 wöchentlichen Embryo gehabt oder nur die sympodische Verschiebung der Bronchialäste erkannt hätte, er nicht die Monopodie für den Stammbronchus hätte behaupten können, dagegen die Dichotomie für das Grundgesetz der Entwickelung des Bronchialbaumes erklärt haben würde.

Auf den Zeichnungen zur Bronchialverzweigung des vierwöchentlichen menschlichen Embryo scheint die Monopodie gar nicht ausgesprochen. Es hat links eine Dichotomie stattgefunden, wonach der eine Ast schon die Leitung übernommen und den ursprünglich gleichwerthigen anderen zur Seite geschoben hat; rechts ist dasselbe schon zweimal vor sich gegangen.

Interessant ist die folgende Bemerkung von $\mathrm{H}$ is: charakteristischer Weise sind die Seitenknospen dem Stammbronchus etwas oberhalb der Stelle aufgesetzt, wo derselbe eine scharfe Knickung erfährt".

Die schon erwähnten Unvollkommenheiten der bildlichen Darstellungsmethode machen diese Knickung unsichtbar. Das beigefügte kleine Schema zeigt, wie ich mir die ersten Verzweigungsvorgänge des rechten Bronchus vorstelle, und das Schema wird sicherlich einem Schnitte durch die H i s'sche Sonder- 
zeichnung des rechten Bronchus entsprechen. Das primitive Bronchialrohr $a$ ist dichotomisch in zwei Blasen $b$ und $c$ getheilt, $b$ ist schon zur Seite geschoben worden, $c$ wächst einigermassen direct vorwärts, sein Fundus flacht sich ab und theilt sich dichotomisch in $d$ und $e$, die noch gleichmässig zu

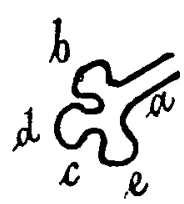
beiden Seiten divergiren. Dadurch entsteht die Knickung, oberhalb der man ganz gut sagen kann, dass die zwei ${ }_{n}$ Seitensprossen ${ }^{*}$ $b$ und $d$ aufgesetzt sind.

Betrachtet man die $\mathrm{H}$ i s'schen Bilder des Stadiums von $8,5 \mathrm{~mm}$ Länge, dann wird man nur am Bronchialstamme im Untergeschoss etwas, das für Monopodie sprechen könnte, finden. Im Falle, dass der Eindruck, den man durch die unmittelbare Betrachtung dieses Bronchus rechterseits gewinnt, wirklich richtig wäre, dann würde das im höchsten Grade für Monopodie sprechen. Dieser Eindruck ist aber sicher falsch. Die optische Verkürzung modificirt vielleicht das Verhältniss sehr bedeutend; die Fehler, die nnabwendbar einer Methode, die so grosse, künstlerische Forderungen stellt wie das Freihandmodelliren, ankleben mïssen, tragen wohl den Hauptantheil der Schuld. Endlich muss ich darauf aufmerksam machen, dass $H$ is ja selbst sagt, dass die äussersten der hier dem Stamme aufsitzenden Sprossen dichotomisch gebildet sind, was die Zeichnung gewiss Keinem zu versteben giebt; genau dasselbe gilt für die Sonderzeichnungen der rechten und linken Lunge des 10,5 mm langen Embryo, wie für das linke unterste Bronchialende des 13,8 cm langen Embryo.

Analogiefolgerungen aus den Verbältnissen der ein wenig späteren Stadien sowie genauere Betrachtung der His'schen Zeichnungen haben mir es also wahrscheinlich gemacht, dass die Bronchialverzweigung vom ersten Anfange bis zum Schlusse eine dichotomisch-sympodische sei. Ich bin jedoch auch nicht ausschliesslich hierauf verwiesen. Die Dntersuchung einiger Schnittserien des königlichen anatomischen Museums in Kopenhagen, die Herr Prof. $\mathrm{C} h$ i e vitz mir gütigst zur Verfigung stellte, hat mir in dieser Frage jeden Zweifel entfernt. Zahlreiche Momente denteten direct darauf hin, dass alle Zweige dichotomisch gebildet waren, nichts gab nur die schwächste Andeutung einer Monopodie, und mit Sicherheit konnte ich constatiren, dass der 
erste linke Seitenzweig bei der Maus und bei der Ratte und der zweite linke Seitenbronchus des Kaninchens dichotomisch gebildet werden.

Bei einem 10,5 mm langen Kaninchenembryo habe ich folgenden Befund erhoben: Die schon ganz vom Oesophagus getrennte Trachea theilt sich in zwei Bronchen, die abwärts und seitwärts divergiren. Der rechte Bronchus entsendet recht schnell einen starken, eparteriellen Zweig, während der linke verhä̈ltnissmässig lange Zeit keinen Zweig abgiebt. Nachdem der linke Bronchus unter die A. pulmonalis gelangt ist, entsendet er seinen ersten Zweig und zeigt an dieser Stelle eine schwache Knickung, die ein Ueberbleibsel der ersten Dichotomie ist und ein Zeugniss davon abgiebt, dass bier der Stammbronchus aus zwei Stücken zusammengesetzt ist. Bei der nächsten Theilung findet sich eine dentliche Knickung, ganz wie $H$ is eine solche beim 4 wöchentlichen menschlichen Embryo gefunden hat. Der eine Zweig läuft schräg nach aussen, der andere gerade nach unten, während der Mutterast mehr schrïg verläuft und dessen Achsenverlängerung ziemlich genau in die Mitte zwischen die zwei Tochteräste fällt.

Diese letzte Theilung ist also eine typisch dichotomiche. Der exacte Beweis, dass anch der erste Ast dichotomisch gebildet sei, fehlt mir freilich, wenn es anch durch dic schwache Knickung des Stammbronchus angedeutet ist. Aber es wäre doch nach den im Vorgehenden mitgetheilten Erfahrungen merkwürdig, anzunehmen: Die Bifurcaturtheilung ist dichotomisch, der erste Seitenbronchus entspringt monopodisch, alle folgenden $\mathrm{Z}$ weige bilden sich dichotomisch. Und dies wïre um so mehr unhaltbar, als für die Monopodie, wie ich nochmals nachdrücklich hervorheben muss, kein einziger Beweis geführt worden ist, nur dieser : die nicht ganz jungen Zweige haben ein monopodisches Aussehen. Das ist aber kein Beweis; dieser Umstand erklärt sich leicht durch die sympodischen Vorgänge, die üherhaupt für die Formverhältnisse des ganzen Bronchialbaumes von durchgreifender Bedeutung sind. Nur einen Beweis für die Monopodie müsste man als gïltig erkennen, wenn es sich nämlich erweisen liesse, dass aus einem schon ausgebildeten cylindrischen Bronchus kleine, seitenständige Ausstülpungen sich bildeten, die später z Bronchen auswïchsen, so wie Stieda es beim Schafsembryo gesehen zu haben meinte. 
Rechterseits in demselben $10,5 \mathrm{~mm}$ langen Kaninchenembryo wird erst ein hyparterieller Ast abgegeben, und der Stammbronchus zeigt wieder bicr eine scharfe Knickung; der erste hyparterielle Zweig sieht vollständig monopodisch aus, danach folgen zwei ganz typische Dichotomien, danach endlich eine abgeflachte Endblase in dem ersten Stadium der dichotomischen Theilung.

Die Bronchialverwweigung ist also eine dichotomische.

Wie verhült sich aber eine Dichotomie zur nächst vorgehenden und zur folgenden?

In seinem trefflichen Werke ïber die Menschenlunge hat Waters auf diese Frage folgende Antwort: ${ }_{n}$ Wenn cin Ast sich zweimal nach einander theilt, kreuzt das Septum der zweiten Theilung das der rechten rechtwinkelig".

Untersuchungen von Serienteichnungen, von Corrosionen und von frischen Lungen, sowie auch von $A$ e by s Zeichnungen haben mir hierüber folgendes gelehrt: Es giebt eine schr starke Tendenz der Theilungen, in abwechselnden, einander rechtwinkelig. schneidenden PJanen zu liegen ${ }^{1}$ ). Des weiteren will icb mich an dieser Stelle hierüber ganz kur" fassen und nur das hervorheben, dass Abweichungen von der genannten Regel auch vorkommen. Es giebt Fälle, wo zwei einander folgende Theilungsplane sich nicht unter $90^{\circ}$, sondern unter ungefähr $120^{\circ}$ kreuzen, und das erklärt sich meiner Meinnng nach dadurch, dass die Ranmverhältnisse solches nothwendig genacht haben. Es sind dies Ausnahmefälle, in denen die Natur sich zur Abweichung von einer Grundregel ge\%wungen gesehen hat. Bei Besprechung der Spiralstellung der Seitenzweige und der Drehung der Schleimhautfalten wird dieses weiter beleuchtet werden.

Es ist erwiesen, dass die Verzweigung sich in der in der Botanik sogenannten sympodischen Form vollzieht. Es liegt dann nahe zu fragen, ob in der Stellung der Aeste zu ihrer Achse auch eine Regel sich erweisen lässt, ähnlich wie die botanische, dass bei einer bestimmten Pflanze immer ein bestimmter Theil der Peripherie zwischen zwei einander folgenden Zweigen liegt, ferner, dass in charakteristischer Weise die Zweige schraubenförmig angeordnet sind.

1) Schon Waters hat dieses angedentet. Die Allgemeingüiltigkeit, die er dem Satze verleiht, besitzt er aber in Wirklichkeit nicht. 
Dieses ist indessen nicht der Fall. Die Zweige entspringen bald mit $90^{\circ}$, bald mit $180^{\circ} \mathrm{Zwischenraum.} \mathrm{Die} \mathrm{Schraube} \mathrm{windet}$ sich bald rechts, bald links um. Dieses lässt sich besonders gut an Corrosionspräparaten untersuchen. Hier fällt dann auch ein anderes Phänomen auf, das in dieser Hinsicht von Bedeutung wäre. Die Corrosionen zeigen nämlich sehr schöne Ausgüsse der in allen ein wenig grösseren Bronchen wohl entwickelten, längslaufenden Schleimhautfalten. Diese zeigen sehr oft eine dentliche Windung, bilden eine sehr lang ausgezogene Spirale der Achse entlang. An einigen Stellen ist diese Windung sebr gering, an anderen recht stark - sie fehlt im Stammbronchus - eine Strecke geht sie links um, und gleich danach geschieht sie eine Weile nach rechts. Wo die Schleimhautfalten die Windungsrichtung ändern, nimmt die Schraube, in der die Bronchialzweige ange. bracht sind, dieselbe Beweynng vor.

Dieses deutet auf eine Verbindung zwischen den zwei Phänomenen.

Was ist es denn, was die Schraubenstellung der Brovchialzweige und deren Variabilität bedingt, und wie entstehen die Windungen der Schleimhautfalten und deren stets wechselnde Intensität und Richtung?

Wenn die dichotomischen Theilungen immer in einander rechtwinkelig sich kreuzenden Planen vor sich gehen, dann ist es klar, dass der Winkelabstand zwischen zwei einander folgenden Zweigen immer $90^{\circ}$ sein muss. Die Neigung zur Bildung von grösseren Schrauben zeigt, dass das Hervorwachsen des einen Zweiges als Hauptachse und das Zurseiteschieben des anderen als Seitenzweig nach einer gewissen Regel geschehen. Wenn nicht specielle Umstände dem entgegentreten, werden die Rollen immer in ganz bestimmter Weise vertheilt.

Eine linksseitige Schraube ist demnach folgendermassen gebildet worden :

1) Dichotomie Nord-Sud. Nord wird Achse.

2) $\quad$ Osten-Westen. Osten wird Achse.

3) $n$ Nord-Sud. Slid wird Achse.

4) " Osten-Westen. Westen wird Achse.

Würde die Schraube sich hier in eine rechtsseitige ändern, 
dann würde das nächste Mal bei der Dichotomie Nord-Süd Süd statt Nord Achsenverlängerung werden.

Ein solcher Wechsel muss, g-laube ich, durch die Rannverhältnisse erklärt werden. In dem eben gegebenen Exenpel wäre damn für ein Auswachsen nach Süden nicht der genügende Platz vorhanden gewesen, und der Schwesterzweig sei dann gegen Norden ausgewachsen.

Eben derselbe Umstand ist es nach meiner Anschauung, welcher die rechten Winkel, die die Theilungsplane in der Regel mit einander bilden, in einigen Fällen modificirt, derselbe wieder, welcher die Windung der Schleimhautfalten hervorruft.

Wenn eine Dichotomie sich in einem Plane gebildet hat, der den vorangegangenen Plan kreuzt, dann ist es leicht denkbar, dass sie in einigen Fällen so zwischen die Nachbarn hinein gedrängt wird, dass sie sich in diesem Plane nicht oder nur schlecht weiterentwickeln könnte. Eine kleine Aenderung des Planes, d. h. eine Rotation des Mutterzweiges, würde vielleicht bessere Wachsthumsbedingungen herbeiführen können, - dadurch würde aber sowohl eine Abweichung von dem regelmïssigen Verhalten der Winkelabstände der Zweige, wie auch eine Windung der Schleimhautfalten bedingt sein.

Der Umstand wieder, dass man im Stammbronchus keine Windung der Schleimbautfalten beobachtet, spricht, scheint mir, dafür, dass diese Anschaung richtig ist. Der Stammbronchus ist unzweifelhaft der von allen Bronchen, dem sich die geringsten Raumschwierigkeiten behindernd entgegenstellen. Alle seine direkten und indirekten Aeste müssen mit anderen Organen und mit einander um den Platz ringen. Er allein findet immer den Weg frei. Rasch und unbehindert wächst er durch die betreffende Thoraxhälfte ihrer Längenachse nach hindurch.

Ist der Winkelabstand zwischen zwei Aesten $180^{\circ}$, dann muss das darin begründet sein, dass der Stamm einmal von seinem Principe abgewichen ist. Er hat sich zweimal nach einander in demselben Plane getheilt, wodurch ein Winkelabstand von entweder $0^{\circ}$ oder $180^{\circ}$ entstehen musste. Einen Winkelabstand von $0^{\circ}$, d. h. $2 \mathrm{Z}$ weige auf einander folgend, gerade über einander sitzend, habe ich niemals gesehen. Einen Winkelabstand ron $180^{\circ}$ dagegen ab und zu. Eine solche Abweichung 
würde wieder aus Raumverhältnissen zu erklüren sein. So finde ich in einer Corrosion einen recht grossen Bronchus, der mit seinen Aesten und deren Lobuli eine ganz Hache, beinahe blattartige Ausbreitung bildet, dielit gegen andere Astgebiete, theils von gleicher, theils von anderer Form, gedruickt. Es scheint, als ob hier nur Platz fuir Theilm!ren in diesen bestimmten Plane gewesen sei, und dem entsprechend entspringen die Aeste hauptsächlich an den zwei Seiten der Achse, während nur wenige und kleine an den zwei anderen Seiten sitzen.

Betrachten wir jetzt menauel den A eby'schen Stammbronchus und seine Zweige, dann zeigt sich hier ein mit den vorhergehenden Darstellungen ïbereinstimmendes Pbänonen:

Die hyparteriellen Bronchien des Mensehen sind theils rentrale, theils dorsale, wozn doch zn bemerken wäre, dass, wie $\mathrm{H}$ is sagt, die ventralen in der That laterale sind, während die dorsalen direet dorsal verlaufen. Die in den zwei Richtmngen abgehenden Aeste alterniren im allgemeincn, doch nicht gan\% regelmässig.

Der Winkelabstand zwisehen den zu den \%wei Reihen gehürigen Aesten ist also 900; die Schraube wechselt aber stets in ilırer Richtung, indem sie bei Abgang jedes Astes von Rechtsdrehung in Linksdrehung und umgekehrt umschliagt. Hier muss also bei jeder Dichotomie der Ziveig, der am meisten medial uni vorne gelegen war, in den Stammbronchus übergewangen sein, wïhrend die lateralen mul hinteren zu Seitenbronchien geworden sind. Dieses lässt sich auch durch directe Untersuchung der entsprechenden Embryonalstadien bestätigen. "Man sicht hier direct und unzweifelhaft, dass die Seitenbronchien durch Dichotomien in rechtwinkelig sich kreuzenden Planen sich bilden und die binteren und lateralen Zweige dieser Dichotomien sind.

Als Ursachen dieses Verhaltens muss man meiner Meinung nach wieder an die Raunverhältuisse denken. Die Wirbelsäule und das Her\% sind Factoren, die wohl die Bildung der Seitenäste in den betreffenden Richtungen hindern können.

Beinahe einen Beweis für die Richtigkeit dieser Vermathung giebt der Bronchus cardiacus ab. Derselbe schiebt sich unter das Herz hinein in einer gerade entgegengesetzten Richtung als die „ventralen", d. h. lateralen Zweige. Er ist, sagt $\mathrm{H}$ is, ein 
wirklich ventraler Seitenbronchus ${ }^{1}$ ). Hier tritt schon die Neigung zur Abgabe von Aesten in alle 4 Hauptrichtungen hervor. Die Entwickelung ist durch die Raumverhältnisse gebunden gewesen. Sobald ihr diese freie Hände geben, treten auch die Gesetze zu Tage, die im ganzen späteren Leben die leitenden bleiben.

A eby giebt Abbildungen von zwei Corrosionspräparaten der ersten Bronchialzweige eines 35 und eines 38 Jahre alten Mannes. Man braucht nur einen Blick auf diese Tafel zu werfen, um zu sehen, wie die zwei Stammbronchien und die ventralen Seitenbronchien sich den Contouren des Herzens anschliessen. Der kürzeren basalen Fläche und dem längeren linken Rand des Herzens entsprechend, bleibt der linke Stammbronchus in einer bedeutend längeren Strecke ohne Aeste als der rechte.

Uebrigens ist der Mensch, wie die Bilder A e b y's zeigen, eine der mit wirklich ventralen Seitenbronchien am spärlichsten verseluenen Arten. Wieder eine Wirkung der Ranmverhältnisse. Der Brustkasten des Menschen ist breit, aber verhältnissmässig flach. Bos taurus hat eine Menge wirklich ventraler Seitenbronchien (A e b y nennt sie ganz willkürlich „Nebenbronchien ${ }^{*}$ ). Der Thorax des Ochsen ist mehr zusammengedrtickt, mit grossem Diam. antero-post. und bietet reichlich Platz an beiden Seiten des Herzens.

Phoca vitulina, Bradypus tridactylus, Auchenia lama, Phascolomys Wombat, Lemur mongoy sind alle mit wirklich ventralen Seitenbronchien ( ${ }^{N}$ Nebenbronchien ${ }^{u}$ ) mehr oder minder reichlich versehen. Untersucht man genauer die von $\mathrm{A}$ eby gegebenen Bilder, und vergegenwärtigt man sich einigermaassen die zwei Hauptdiameter des Thorax der Thierspecies, von dessen Lungen er Präparate abbildet, überlegt man den Platz und die Zahl der angegebenen Nebenbronchien, vergleicht man diese Verhältnisse mit einander und mit der Lage des Herzens, so spricht, scheint mir, alles dafür, dass es das Herz und die Wirbelsäule sind, die in einigen Fällen und auf gewissen Strecken des Stammbronchus die Bildung medialer und ventraler Bronchien hindern.

Der eparterielle Bronchus des Menschen ist nacb A eby und $\mathrm{H}$ is dorsoventral, entspringt ungefähr in der Mitte zwischen

1) besser doch medial. Verf. 
den zwei hyparteriellen Reihen. Diese seine Lage scheint mir, angesichts der Grösse des besagten Bronchus und der grossen Nähe, in der die zwei Reiben nebeneinander liegen, ohne zwingende Bedeutung, kann wenigstens nicht die Ansicht, dass der eparterielle Bronchus etwas ganz eigenartiges sei, rechtfertigen. Ihm gegenuiber haben sich specielle Verbältnisse geltend gemacht, die in seiner eparteriellen und dorsoventralen Lage, sowie im Mangel von etwas morphologisch entsprechendem in der linken Lunge, endlich in einer Besonderheit seines Abstandes von dem ersten hyparteriellen Bronchus bestehen.

Alle die Argumente, durch welche A eby aus dem eparteriellen Bronchus ein für die betreffende Lunge spexielles Organ, dem nichts entsprechendes in der anderen sich findet, machen will, scheinen mir sehr schwach, mehr theoretisch als practisch erwiesen, und diese Lehre scheint mir ganz zu Boden zu fallen, wenn man den Verzweigungsmodus auf diesem Stadium für dichotomisch ansiebt. Zwar babe ich nicht durch directe Untersuchungen die absolute Nichtexistenz der monopodischen Verzweigung des Stammbronchus beweisen können. Das Gebiet, auf dem die Monopodie noch nicht direct und vollständig ansgeschlossen ist, müssen wir aber jetzt als so minimal bezeichnen, und es sprechen so zwingende Gründe gegen ihre Existenz, dass sie als beinahe ausgeschlossen angesehen werden kann.

Mir scheint also, dass man die zwei Aeste, die jederseits durch die erste Dichotomie gebildet worden sind, für homologe ansehen muss. Der rechte eparterielle Bronchus entspricht genetisch dem ersten hyparteriellen linkerseits. Die anatomische Assymmetrie wird physiologisch dadurch compensirt, dass der eparterielle Bronchus rechts gemeinsam mit dem ersten hyparteriellen ein Gebiet kanalisirt, das eben dem linksseitig von dem ersten hyparteriellen, reich entwickelten $\mathrm{Z}_{w}$ eige allein versorgten entspricht. Die Bildung der zwei Lappen rechts ist eine secundäre Wirkung, einfach durch die Assymetrie des Gefässsystemes bervorgerufen, und wenn der linke, obere Lungenlappen ungetheilt geblieben ist, dann ist derselbe Umstand der entscheidende gewesen, indem die erste Dichotomie des linken Stammbronchus etwas später erfolgt ist als die der rechten, nämlich erst nachdem der Bronchus unter die A. pulmonalis gelangt war. 
Zur Entwickelung und Verzweignng des Bronchialbaumes etc. 637

Eine weitere Consequenz daraus, den Stammbronchus als durch zahlreiche Dicbotomien aufgebaut anzusehen, ist, dass man eigentlich nicht berechtigt ist, von einem Stammbronchus wie von einer primären Achse und von dessen Seitenzweigen als von Bronchien erster Ordnung zu sprechen. Der Stammbronchus ist aus zablreichen Stücken höchst verschiedener Ordnung zusammengesetzt, und jeder seiner Seitenzweige bat dieselbe Ordnung, wie das eben vor seinem Abgang hefindliche Glied des Stammbronchus. So schwindet auch das merkwürdige Verhältniss, dass man in der Spitze des Stammbronchus einen kleinen Zweig erster Ordnung, ja den Stammbronchus selbst direct in die Alveolensysteme ïbergehen sehen kann, während dieses an mehr centralen Stellen eine sehr grosse Anzahl von Generationen in Anspruch nimmt.

Die Abstände zwischen zwei einander folgencien Aesten betreffend, so müssen dieselben ja von der Schnelligkeit abhängen, mit der die dichotomischen Theilungen einander folgen und von der Grösse des späteren Wachsthumes. Diese Schnelligkeit ist, wie die Corrosionspräparate und die Schnittserien tibereinstimmend zeigen, sehr wechselnd. Selbstverständlich sind die Abstände im allgemeinen sehr viel grösser bei dem erwachsenen Thiere als bei Embryonen, grösser bei den grossen als bei den kleinen Bronchien. Allen gemeinsam ist nur die grosse Variabilität der Abstände.

Aus einem Corrosionspräparate eines 2 Tage alten Kalbes entnelıme ich ein Stück Bronchus folgender Dimensionen: Länge $4,5 \mathrm{~cm}$. Lumen des centralen Endes 1,7, das des peripherischen $1 \mathrm{~mm}$. Es gehen hier 15 Zweige $a b$ und zwar in folgenden Abständen : $\quad 4,5-1,5-2-3-2,5-0,5-3-1,5-2-1,5-2,5-$ $2,5-2-1,5 \mathrm{~mm}$.

Durch eine Serie von 200 Schnitten habe ich einen kleineren Bronchialstamm eines $44 \mathrm{~cm}$ langen Ochsenembryo verfolgt. Es gingen $15 \mathrm{Zweige} a b$ in folgenden Abständen: 12$8-16-16-17-14-15-11-26-2-12-5-10-4$ Hundertelmillimeter.

Ganz entsprechende Resultate ergibt die Untersuchung eines aufgeschnittenen Stammbronchus.

Lumenverbältnisse der Zweige: Es folgt beinahe von selbst, 
dass die vom Stammbronchus entspringenden Zweige stets kleiner werden, je mehr peripherisch sie diesem aufsitzen. Dieses Abnehmen der Lumina erfolgt aber mit grosser Unregelmässigkeit. Untersucht man einen aufgeschnittenen, axialen Bronchus, oder nimmt man einen solchen aus einem Corrosionspräparate, dann findet man überall zwischen den grösseren Zweigen ganz kleine hie und da ohne nachweisbare Regel angebracht. Dieser Unterschied unter den Aesten einer gewissen Region findet sich aber nur auf älteren Achsen. Er ist deutlich genug im Wachsthume entstanden. In den ganz jungen Generationen macht sich immer eine ganz andere Gleichartigkeit geltend.

Dieser Entwickelungsunterschied ist, glaube ich, kein priidestinirter, sondern er hat sich secundär unter dem Einflusse der Raumverhältnisse oder - was wohl dasselbe bedeutet der Ernäbrungsbedingungen entwickelt. Die dünneren Aeste breiten sich nur in einem mehr beschränkten Bezirk aus, in welchem sie sich sehr schnell in eine Menge von ganz kleinen Aesten auflösen. Sie sind den grösseren Zweigen gegenüber quantitativ minderwerthig, womit aber, wie später gezeigt werden wird, sicherlich keine qualitative, physiologische Minderwerthigkeit folgt. Diese Erfahrungen stimmen mit dem von Braune und Stabel gefundenen Gesetze überein, dass die Grösse eines gewissen Bronchialdurchschnittes von der durch das Lumen $\mathfrak{z u}$ befördernden Luftmenge abhängig ist.

Eine zweite Form von Lumendifferenz ist die, dass ein Seitenzweig in den älteren Abschnitten der Lunge in der Regel enger ist als das Stück des Achsenstammes, das ihm homolog ist, so die Seitenbronchien enger als das ihnen entsprechende Stuck des Stammbronchus.

Aus diesen Unständen folgt, dass mit Angabe der Weite eines Bronchialastes mit Rücksicht auf seine centrale und peripherische Lage eigentlich nichts gesagt ist. Es muss die Generation des betreffenden Bronchialdurchschnittes angegeben werden, weiter mindestens, ob der Durchschnitt im Stammbronchus oder einem der grösseren axialen, lobären oder lobulären Bronchien gelegen ist.

Wir verlassen jetzt die mehr dem Embryonalleben angehörigen Fragen und wenden uns den Verhältnissen des postembryonalen Zustandes, speciell den Alveolensystemen, zu. 
Zur Entwickelung und Verzweigung des Bronchialbaumes etc. 639

Seit 200 Jahren ist die erwachsene Lunge ein Objekt wissenschaftlicher Forschung. Die sehr interessante, ältere Geschichte, in der besonders die Namen von Malpighius und Reisseissen hervorleuchten, werden wir hier bei Seite legen müssen. Nur das wollen wir erwähnen, was man uns seit Mitte dieses Jahrhunderts äber die feineren intralobulären Verzweigungen berichtet hat.

Waters findet im Lobulus monopodische, dichotomische und trichotomische Theilungen.

"The number of dichotomous divisions, which take place, from the entrance of the bronchial tube into the lobe, to its termination in the tube, which have connected with it the ultimate ramifications, varies, according to the distance of this latter from the point of departure of the lobular bronchial tube. I have found the fifth, sixth, seventh and eight divisions the last."

Die Aeste sollen in mehr centralen Gebieten mehr stumpfwinkelig; in den peripherischen mehr rechtwinkelig abgehen.

Waters findet in der Regel beim Menschen keine Alveolen am Terminalbronchus, nur in den Infundibula.

An einer gewissen Stelle erweitert sich der terminale Bronchus in eine Cavität, in welche mit Alveolen besetzte Candle, "air sacs", einfach oder schwach getheilt, in einer Anzahl von 6-8-10 münden.

Schulze findet beim Menschen dichotomische Theilungen, bis das Lumen der Bronchien auf $4 \mathrm{~mm}$ herabgestiegen ist. Dann hören die dichotomischen Theilungen auf, und es werden jetyt spiralig angeordnete, mit dem Stamme Winkel von ca. $45^{\circ}$ bildende monopodische Aeste abgegeben. Von diesen gehen wieder Aeste unter beinahe rechten Winkeln aus: „Die respirirenden Hohlräume stellen rundliche Gänge dar, welche unter zwei- bis viermaliger, spitzwinklig-dichotomischer Theilung auf einer Entfernung von 2-4 $\mathrm{mm}$ von jedem Bronchialende aus sich verzweigend mit kleinen, meistens trichterförmig sich erweiternden Endauslä.ufern und ähnlich gestalteten seitlichen Aestchen - beide wegen des verhältnissmässig engen Einganges und weiten Grundes infundibula genannt - blind endigen." Schulze giebt diesen Infundibula die Bezeichnung Alveolarginge.

Kölli ker beschreibt, wie Alveolen erst vereinzelt an einer Seitenwand sich einstellen, dann hier zahlreicher werden und dann erst stufenweise über die ganze Innenwand des Rohres sich ausbreiten, wodurch aus einem Bronchiolus respiratorius ein Alveolengang gebildet wird.

Mill e r findet, dass in der Hundelunge aus einem Terminalbronchus eine Anzahl "passages" entspringen, die in je eine Erweiterung übergehen. Hiervon gehen neue Passages aus, die sich wieder in Cavitäten öffnen, deren Wände mit Alveolen besetzt sind. Miller vergleicht das System mit der Einrichtung eines pompejischen Hauses: Vom Terminalbronchus gehen aus Vestibula, die in Atria einführen, aus diesen 
leiten Fances "air-sac-passages ${ }^{a}$ ) in Peristyla ( ${ }_{n}$ air sacs $^{*}$ ), die mit Cubicula ( ${ }$ air-cells", Alvenlen) besetzt sind, ein. Es finden sich Alveolen am Terminalbronchus, am Atrium und an den Air-sacs.

Die Air.sacs sind ungefahr doppelt so gross wie das Atrium.

Die Anzahl der verschiedenen Hohlkörper der Hundelunge giebt uns Miller in der folgenden Tabelle:

Trachea 1, R. and L. Bronchi 2, Lobar Bronchi 6, 1. Order Bronchi 24, 2. Order Bronchi 164, 3. Order Bronchi 1021, Lobular Bronchi 16000, Atria 64000, Air Sacs 192000, Air-cells of Bronchi 320000 , Air-cells of Atria 320000, Air cells of Air-sacs 1920000 , Total of Air. cells 2560000 .

Leider erzählt Miller gar nicht, wie or die Zahlen dieser Tabelle gefunden hat.

Die Anschauungen Aeby's über den Verzweigungsmodus der Bronchien haben wir schon kennen gelernt. Hier sollen nur einige von ihm herrührende Angaben über die Zahl der Alveolen besprochen werden.

Aeby kritisirt die Angabe Huschke's, nach welcher die zwei menschlichen Lungen zusammen 1700-1800 Millionen Alveolen enthalten sollen. A eby berechnet, dass das Weib 322,500000, der Mann 404,500000 Alveolen besitzt. Als Grundlage der Rechnung dient folgendes: Der durchschnittliche Diameter der Alveolen ist $1 / 5 \mathrm{~mm}$; die Form der Alveolen schwankt um eine Kegelflïche. Jeder Alveolus fasst dann $1 / 250$ cbmm. Jedes cbmm Lungensubstanz enthält also 250 Alveolen. In $1617 \mathrm{cbmm}$ Lungensubstanz sind 404,500 000, in $1290 \mathrm{cbmm} 322,500000$ Alveolen enthalten.

Ich werde jetzt zu meinen eigenen diesbeziiglichen Untersuchungen übergehen. Wir werden uns jetzt nur für die Alveolensysteme, fur den wirklich respiratorischen Theil der Lunge interessiren, lassen also die auch innerhalb des Lobulus sehr zahlreichen, einfach luftleitenden Bronchiolen, die ganz die schon beschriebenen Verhältnisse darbieten, vollständig bei Seite.

Als Ausgangspunkt nehmen wir einen Bronchiolus direkt am Uebergang vom luftleitenden in das respirirende System.

Dieser Uebergang vollzieht sich bei dem Ochsen ganz plötzlich; mit einem Schlage ist der Bronchiolus dicht mit Alveolen besetzt und nur von respiratorischem Epithel ausgekleidet.

Genau an der Uebergangsstelle geht immer ein Seitenzweig rechtwinkelig zur Seite $a b$, ebenfalls mit Alveolen besetzt und mit respiratorischem Epithel bedeckt. Wir werden später auf diesen Zweig zurückkommen. Der Hauptast, den wir vorläufig verfolgen wollen, streckt sich ein Stückchen direkt weiter vorwärts, theilt 
Zur Entwickelung und Verzweigung des Bronchialbaumes etc. 641

sich dichotomisch, indem die zwei dadurch gebildeten Aeste einigermaassen gleichmässig ziemlich spitzwinkelig divergiren, um plötzlich in je einer grossen Cavität zu enden, wovon blind endigende, kurze Schläuche ausgehen.

Anders ausgedruckt: Ein Bronchiolus simplex bildet dichotomisch zwei Bronchioli respiratorii, diese dichotomiren; in jedem der so gebildeten Bronchioli respiratorii zweiter Ordnung entsteht eine Cavität, die wir mit Miller Atrium nennen werden, und von hier gehen wieder kurze Schläuche aus, die wir mit demselben Verfasser sacci aërei nennen.

Das Atrium kann von wechselnder Grösse sein, ist bald wohl ausgesprochen und leicht zu sehen, bald findet es sich nur als eine geringe Anschwellung des Bronchiolus, dann weniger in die Augen springend. Jedenfalls glaube ich doch, dass man Miller darin beipflichten muss, dass diese Cavität ein wohl ausgebildetes Element ist, das eine eigene Benennung verdient. Man kann es nämlich, so viel ich sehe, nicht einfach als die Vereinigungs- oder Ursprungsstelle der letzten Zweige, der sacci aërei ansehen. Sieht man doch oft ihre Ursprünge von Wandstrecken einer gewissen Breite von einander geschieden, welche man absolut als dem Atrium als solchem zugehörig ansehen muss.

Etwas anderes ist es, dass das Atrium meiner Meinung nach durch dichotomische Vorgänge und zwar durch zwei anfeinander folgende gebildet worden ist. In Lungen von $80 \mathrm{~cm}$ langen Embryonen sieht man nämlich gar nicht solche selbstständige Wandparthien. Diese werden erst später durch ein secundäres Wachsthum gebildet. Ursprünglich wird eigentlich die ganze Wand des Atriums von den in die sacci aërei einfuhrenden Löchern eingenommen.

Die Zahl der sacci aërei giebt Miller als 3 oder mehr für jedes Atrium an, Waters findet beim Menschen 6-8-10.

Meine Erfahrungen lassen sich mit diesen Angaben nicht in Uebereinstimmung bringen. Bei dem $80 \mathrm{~cm}$ langen Embryo habe ich eine Menge von Alveolensystemen untersucht und niemals andere Zahlen als 4 sacci aërei von je einem Atrium ausgehend gefunden. Diese 4 entspringen weiter - man erinnere, dass sie in diesem Stadium ganz jung und neugebildet sind - so, dass jeder einen Winkel einer 4seitigen Pyramide bildet. Weiter: 
schliessen sich ihre Ursprünge je zwei und zwei zusammen. Kurz and gut, alles deutet dahin, dass sie nicht als mehr oder minder zufällige Auswüchse aus der Wand des Atriums entstehen, sondern durch zwei schnell einander folgende in rechtwinkelig sich kreuzenden Planen gestellte Dichotomien gebildet worden sind.

Ist diese Auffassung richtig, dann leuchtet sofort ein, dass man solche Zahlen wie die von Waters und Millers angegebenen $6-8-10$ und 3 ïberhaupt nicht wird finden können. Die Zahl muss nothwendig eine Potenz von 2 sein. Inzwischen habe auch ich in Lungen von erwachsenen Ochsen Atrien gefunden, von denen nur drei sacci aërei auszugehen schienen, oder wo wenigstens der vierte nur ganz schwach angedeutet war. Ich glaube aber, dass dies durch sekundäre Aenderungen bedingt ist, dass immer 4 Luftsäckchen angelegt worden sind, dass aber das eine, wahrscheinlich unter Einfluss schlechter Raumbedingungen, später unterdruckt worden ist. Verschiedene Thatsachen deuten in diese Richtung: Immer findet man einen bedeutenden Unterschied in der Ausbildung der einem. gemeinsamen Atrium zugebörigen Luftsäckchen. Einige sind sehr gross, ja sehr oft tief getheilt, andere sind nur ganz klein. Das letrte habe ich zum Beispiel in solchen Fällen gesehen, wo ein Atrium direkt unter der Oberfläche eines Lobulus belegen war. Hier kann man einen saccns aëreus, der bei seinem Wachsthume auf die Ober. fläche stösst, ganz klein bleiben sehen, wiihrend sein Schwesterzweig, der in den Lobulus hineinwächst, sich kräftig und reichlich ausbildet. Die Raumverhältnisse und die sympodische Verschiebung, die man sich hier wie überall im Bronchialbaume vollziehen denken muss, gelangen sie auch hier nicht zu einer so deutlichen Ausprägung, tragen, glaube ich, die Schuld, wenn man die Luftsäcke in einer Zahl, die keine Potenz von zwei ist, vorfindet.

Dass Waters die grosse Anzahl so gefunden hat, kann selbstverständlich in anderen Verhältnissen der Menschenlunge begrïndet sein; freilich ist vielleicht wahrscheinlicher, dass er einen getheilten Hohlraum für zwei einzelne genommen habe. Waters hat die Verhältnisse an der Hand einzelner dicker Schnitte des Lungengewebes studirt. Diese Verhältnisse lassen 
sich aber nicht durch solche, sondern nur durch Serien von dïnnen Schnitten studiren.

Die Luftsäcke entspringen in der Regel aus dem Atrium mittelst verhältnissmässig enger Oeffnungen, erweitern sich danach bedeutend und schliessen mit einem einfacben oder getheilten Fundus ab. Während Miller beim Hunde die sacci ungefähr doppelt so gross wie das Atrium findet, habe ich beim Ochsen das Atrium immer bedeutend grösser als die sacci gefunden.

Die typische Form der Alveolensysteme des Ocbsen ist demnach die folgende: 2 Generationen Bronchioli respiratorii, von denen die letzte in ein Atrium ausmündet, woraus wieder 4 sacci aërei ausgehen, alles dieses dicht mit Alveolen besetat.

Nach Kölliker treten das respiratorische Epithel und die Alveolen erst an einer Seite des Bronchiolus auf und breiten sich dann stufenweise tiber die weitere Ausdehnung des Bronchialrohres aus.

Ich finde, wie gesagt, beim Ochsen, wo das respiratorische Epithel niemals ausserhalh der Alveolen zu finden ist, diese mit einem Schlage über die ganze Wand verbreitet. Bisweilen sieht man doch, dass ein Bronchiolus an seiner einen Wạd dicht mit Alveolen besetzt ist, während die gegenüberliegende Wand in einer gewissen Ausdehnung keinen einzigen Alveolus besitzt und mit dem einfachen kubischen, regelmässigen, den luftleitenden Bronchiolen charakteristischen Epithel ausgekleidet ist. In solchen Fällen wird man aber immer ein grösseres Blutgefäss dicht der Wand des Bronchiolus anliegend und genau in derselben Ausdehnung, wo die Alveolen fehlen, derselben folgend, finden. Sobald das Gefäss sich ein wenig von der Wand entfernt oder sich in Capillaren auflöst, treten die Alveolen am Bronchiolus auf, wo sie bisher noch feblten, und wo dieser an der Uebergangsstelle von dem luftleitenden in den respirirenden Abschnitt nicht ein solches Gefäss auf sich liegen hat, treten auch immer die Alveolen in einem und demselben Augenblick uber die ganze Peripherie des Rohres auf. Ich glaube also, dass ein solches Gefäss einfach das Hervorwachsen der Alveolen auf der entsprechenden Strecke mechanisch verhindert.

Frïher wurde schon erwähnt, dass die sympodischen Vor- 
gänge sich in den Alveolensystemen besonders schön beobachten liessen.

Am Uebergange des nur luftleitenden in den respiratorischen Abschnitt des Bronchialbaumes seben wir die grösstmögliche Assymmetrie, alsbald aber sieht man diese sich in eine fast vollkommene Symmetrie, die unter den Luftsäckchen und deren dichotomischen Theilungen herrscht, umwandeln.

Vergleichen wir hiermit die Verhältnisse eines $80 \mathrm{~cm}$ langen Embryo, dann sehen wir die zwei Bronchioli respiratorii erster Ordnung fast ganz symmetrisch divergiren; und jedenfalls sind die folgenden wie alle weiteren absolut gleichmässig und symmetrisch.

Geben wir noch einen Schritt zurïck zu dem $60 \mathrm{~cm}$ langen Embryo, wo der Uebergang zwischen den zwei Abschnitten schon deutlich ausgeprägt ist, dann ist auch die erste Dichotomie des respiratorisehen Systems eine vollkommen symmetrische. Dasselbe ist natürlich auch bei dem $44 \mathrm{~cm}$ langen Embryo, die erste Stufe, wo ich Alveolen gefunden habe. der Fall.

Die Sympodie bedingt aber noch weitere Phänomene, die mir von dem grössten Interesse scheinen und die sich am leichtesten in den Alveolensystemen konstatiren lassen.

Wir haben frither einen Bronchiolus respiratorius bis $z u$ der Peripherie verfolgt, haben aber den Ast, den er gleich am Beginne rechtwinkelig abgab, vorläufig ganz bei Seite gelassen.

Folgen wir jetzt attch diesem in derselben Weise, dann zeigt sich, dass er sich genau ebenso wie der Schwesterzweig verhält. Er theilt sich in zwei Aeste, die je in ein Atrium, von welchem wie vorher sacci aërei ansstrahlen, ubergehen. Nur ist dieser $\mathrm{Zweig}$ dem anderen gegenüber ein wenig minder entwickelt. Die Dichotomien folgen sich so schnell, dass die ganze Verästelung in all ihren Componenten kleiner wird; die Anzahl der Generationen aber so wie die Art der einzelnen Theile ist hier wie in dem früher verfolgten Falle.

Schon bier gewahrt man das Gesetz: 2 Schwesterzweige haben denselben anatomischen Bau, und die Anzahl der Theilungen ist in beiden die gleiche. Nur einen quantitativen Unterschied giebt es unter ibnen insoweit, wie der die Fortsetzung des Stammes bildende etwas grösser wird und demnach seine Ver- 
Zur Entwickelung und Verzweigung des Bronchialbaumes etc. 645

zweigungen ïber ein grösseres Gebiet verbreiten kann als der etwas kleinere, mehr concentrirte Seitenzweig.

Mir leuchtete doch das Gesetz erst dann ein, als ich noch eine andere, grössere Untersuchung gemacht hatte.

Es war auffallend, dass die aus der Achse hervorgehenden Zweige peripherisch immer einfacher wurden. Ich wählte dann einen Bronchiolus aus, verfolgte alle seine Aeste bis zu deren äussersten Enden, merkte mir dabei die Anzahl der Ver"zweigungen jedes einzelnen and zeichnete allmählig die Resultate in Form des beigefügten Schemas auf. Der älteste Ast beginnt mit einem kurzen, nit einfachem Bronchialepithel bekleideten Stamme. Dieser theilt sich zweinal und mit der zweiten Theilung ist das einfache Epithel verschwunden, die Aeste sind jetzt iiberall mit Alveolen bedeckt. Wieder Dichotomie, wonach die Bildung der Atrien und Sacci aërei erfolgt. Alle diese Theilungen geschehen den früher beschriebenen Regeln gemïss in verschiedenen Plänen.

Etwas höher hinauf entspringt der nächste Ast. Dieser dichotomirt so schnell, dass eben eine Spur eines ungetheilten Astes überbleibt. Die neu gebildeten Aeste tragen Alveolen. Wieder Dichotomie. Atria. Sacci aërei.

Wieder etwas höher finden wir einen ganz

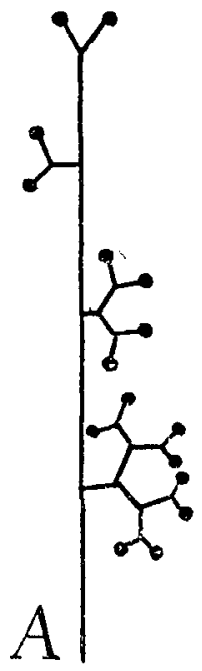
kurzen mit Alveolen bekleideten Ast abgehen; nach Dichotomie bilden sich Atrien.

Jetzt trägt auch die Achse selbst Alveolen. Bald theilt sie sich dichotomisch, und dann treten wieder hier die Atrien und die sacci aërei auf.

Wenn wir jetzt das Schema betrachten, dann wird es sofort auffällig, dass jeder der Seitenäste der Fortsetzung des Stammes mit allen seinen weiteren Verzweigungen homolog ist. Der erste Zweig trägt 8 Atrien, eben dieselbe Zahl wie der Stamm und dessen zwei weitere Aeste. Der zweite Zweig bildet 4 Atrien, ganz wie der Stamm mit dessen letztem Zweig, von welchem jeder 2 Atrien trägt.

Betrachtet man nicht die Zahl der Atrien, sondern äie der 
Verzweigungen oder das Verhältniss der Alveolen, von welchem Ausgangspunkte immer, wird man $z \mathfrak{u}$ dem Resultate kommen, dass jedes seitenständige Astgebiet der Fortsetzung des Stammes mit dessen Aesten entspricht.

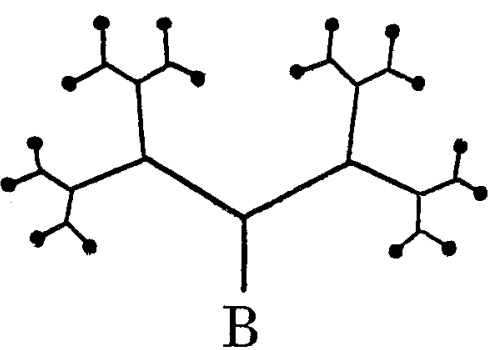

Wir können jetzt das Schema $B$ zeichnen und sehen hier, wie das alles durch dichotomische Theilungen angelegt ist. Das Schema $A$ zeigt dem gegenüber, wie die Sympodie die Verhältnisse geändert hat.

Diese Beobachtungsreihe

rührt von einem $80 \mathrm{~cm}$ langen Ochsenembryo her; später habe ich sie aber in grösserem Maassstabe an den Alveolensystemen des erwachsenen Thieres, sowie am Bronchialbaume jüngerer Embryonen öfter wiederholt, und immer ist das Resultat dasselbe gewesen. Jeder Seitenast trügt halb so viele Atrien wie der vorhergehende, doppelt so viele als der nachfolgende.

Gilt aber dies Geset\% in der ganzen Ausdehnung des Bronchialbaumes? Ist es so der Fall, dann muss z. B. der eparterielle Bronchus des Menschen dem ganzen Reste der beiden Lungen homolog sein und eine eben so grosse Anzahl Atrien wie diese tragen.

Oder haben - so könnte man das Gesetz aluch ausdrücken - die Aeste, die unmittelbar die Atrien tragen, überall in der Lunge dieselbe Ordnung, und ist diese Ordnung für jede Art eine bestimmte?

Zuerst habe ich versucht, dieser lrage auf den fribesten embryonalen Stadien näher zu treten. Hier gilt aber, wie man sofort sieht, das Gesetz nicht. Ein Seitenzweig theilt sich nicht so viele Mal wie die Achse, aus der er entspringt. Schon die Betrachtung der von $\mathrm{H}$ is gegebenen Constructionsbilder zeigt dies unzweideutig, und eine Untersuchung der Anzahl der Verzweigungen des eparteriellen Bronchus und des Stammbronchus von ganz jungen Ochsenembryonen zeigt noch deutlicher, dass die Verhältnisse hier nicht so liegen, wie ich nach dem vorigen erwartet habe. Der Stammbronchus entwickelt und verzweigt sich offenbar mit viel grösserer Schnelligkeit als seine Seitenzweige, 
Zur Entwickelung und Verzweigung des Bronchialbaumes etc. 647

wodurch auch das Verhältniss erklärt wird, das ich mit Rücksicht auf die äussere Form der Lunge constativt habe, dass nämlich der Querdurchmesser zum Längendurchmesser der Lunge ein grösserer ist, je jünger das untersuchte Embryonalstadium ist.

Dass das Gesetz für die frühesten Embryonalsystadien nicht giltig ist, beweist aber nichts mit Rücksicht auf seine eventuelle Giltigkeit in der voll entwickelten Lunge. Die Seitenäste holen vielleicht später ein, was sie dem voraus geeilten Stammbronchus gegeniiber frïher verloren haben. Und dies wird in der That durch die jetat folgende Untersuchung sehr wahrscheinlich gemacht. Ich habe den Stammbronchus einer Schweinelunge, soweit es durch die Scheere möglich war, aufgeschnitten und die Zahl der an dieser Strecke abgehenden Aeste festgestellt. Die weitere Fortsetzung wurde mit dem Microtom in Schnitte quer zur Längenachse zerlegt, dann wurlen die hier abgehenden Seitenäste gezählt. In derselben Weise wurde der eparterielle Bronchus behandelt.

Es stellte sich dann sofort heraus, dass in diesem letzteren, der ungeführ halb so lang wie der Stammbronchus war, die Ursprünge der Seitenzweige viel dichter lagen als in diesem, und die gesammte $\mathrm{Zahl}$ der abgehenden Seitenäste des luftleitenden Systemes - mit dem Auftreten der Alveolen hörte ich mit dem Zählen auf - wal in beiden Fällen dieselbe, nämlich 39.

$\mathrm{Ob}$ der luftleitende Abschnitt der Schweinelunge nun immer aus 39 Generationen besteht, kann ich nicht sagen. Es ist mir bisher nicht die nothwendige Zeit gegeben worden, die Frage weiter zu untersuchen; ich hoffe aber binnen nicht zu langer Zeit weitere Aufschlüsse in dieser Hinsicht geben zu können.

Der oben ausgesprochene Gedanke scheint mir jetzt sehr wahrscheinlich zu sein: der obere Lappen entspricht dem ganzen Reste der gesammten Lungensubstanz. Dass er so viel kleiner ist, schliesst dieses nicht aus, indem alle Zweige hier viel kürzer und enger als besonders im untersten Lappen sind.

Unter dieser Voraussetzung und unter der weiteren Voraussetzung, dass das Gesetz nicht nur für das Verhältniss zwischen diesen zwei Zweigen, sondern für alle Zweige des ganzen Bronchialbaumes gilt, was wohl anzunehmen ist, kann man mit absoluter Genauigkeit die Zahl der respiratorischen Systeme berechnen, 
Betrachten wir das ganze respiratorische System als eine Bildung für sich, die wir Verzweigung 40ster Ordnung nennen wollen, dann ist die Zahl dieser Systeme in der rechten Lunge des Schweines gleich $2^{40}=1,099,511,627,776$.

Wie viele Alveolen sich in einem respiratorischen Systeme befinden, vermag ich im Augenblick nicht zu sagen. Sicher ist aber, dass 100 eher eine zu geringe Zahl ist. Wollten wir aber einmal damit rechnen, dann würde sich herausstellen, dass in den beiden Schweinelungen ca. 110 Billinnen Alveolen enthalten sind.

Erst nachdem die ganze hier mitgetheilte Arbeit vollendet war, ist mir znfälligerweise die $\mathrm{M}$ in ot'sche Embryologie in die Hände gekommen, und ich habe da gesehen, dass $\mathrm{M}$ i n o t schon 1892 die sympodische Verschiebung der Bronchialzweige auf dichotomischer Basis gesehen und beschrieben hat.

Wenn ich erst so spät hiervon Kenntniss bekommen habe, dann ist dic Ursache die, dass ich nur Monographien und Specialabhandlungen gelesen habe, Handbücher nur, wenn ich sie citirt gesehen habe.

Minot spricht sich itber die Frage sehr kurz aus. Ich theile hier seine eigenen Worte und seine ganze Ausführtung mit: "The brancbing occurs in a bighly characteristic manner, for the stem always forks, but the forks develop unequally, one (terminal bud) growing more rapidly and becoming practically the continuation of the main stem, while the other (lateral bud) appears as a lateral branch. Speaking in general, it may be said that the ventral fork serves as the stem - it is erroneous to suppose, as did A e by, that the system of growth is strictly monopodial, it being in reality a modified dichotomous system. The branches all arise by terminal forking, never as outgrowths from the side of a stem. - A e b y - and $\mathrm{H}$ i s seems to accept his wiew - inferred that the right lung contained a bronchus not represented in the left lung. I think, hovewer, that this wiew is untenable and that the right and left first branches are homologous; the difference between the two sides is due to the precocious development on the right side, and to secondary modifications of the arteries".

M in ot's Entdeckung scheint sehr wenig bekannt gewor- 
Zur Entwickelung nnd Verzweigung des Bronchialbaumes etc. 649

den zu sein. Auch in ganz neuen embryologischen Handbüchern, die ich jetzt nachgeschlagen habe, finde ich sie nicht erwhnt. Die Darstellung des Verzweignngsmodus ruht stets auf den $\mathrm{His}$ 'schen oder wohl auch auf den Aeby'schen Anschaunngen.

\section{Literatur - Verzeichniss.}

Aeby: Der Bronchialbaum der Säugethiere und des Menschen. Leipzig 1890.

His: Zur Bildungsgeschichte der Lungen beim menschlichen Embryo. Archiv für Anatomie und Physiologic. 1887.

Miller: The lobule of the lung and its blood-vessels. Aratomischer Anzeiger. 1892.

Minot: Human Embryology. New-York. 1892.

v. Baer: Ueber Entwickelungsgeschichte der Thiere. Königsberğ 1828. Bisch off: Entwickelungsgeschichte des Hundeeies. Braunachweig 1845. Remak: Untersuchungen über die Entwickelung der Wirbelthiere. 1851. Kölliker: Mikroskopische Anatomie. Leipzig 1852.

Jalan de la Croix: Die Entwickelung des Lungenepithels und der Einfluss der Athmung auf dasselbe. Archiv für mikroskopische Anatomie Bd. 22. 1883.

Kölliker: Entwickelungsggeschichte des Menschen und der höheren Thiere. 1879.

Waters: The anatomy of the human lung. London-Liverpool 1860.

Küttner: Studien über das Lungenepithel. Virchow's Archiv. 1876.

Mandl: Anatomie microscopique Vol. II. Paris 1848-57.

Stieda: Einiges über den Bau und Entwickelung der Säugethierlungen. Zeitschrift für wissenschaftl. Zoologie Bd. XXX. Supplement. 1878.

Cadiat: Des rapports entre le développement du poumon et sa structure. Journal de l'anatomie et de la physiologie. 1877.

Derselbe, Structure et développement du poumon. Gazette medicale de Paris. 1877.

His: Anatomie menschlicher Embryonen.

Miller: The struction of the lung. Journal of Morphology. 1893.

Soemmering und Reisseissen: Ueber die Struktur, die Verrichtung und den Gebrauch der Lungen. Berlin 1808.

Reisseisseu: Ueber den Bau der Lungen. Berlin 1822.

Malpighius: De pulmonibus. Epistolae duae ad Borellum. Opera omnia. Londini 1687.

Bartholinus: De pulmonum substantia et usu. Hafniae 1663.

Willes: De respirationis organis et usu. Opera omnia. Genevae 1680. 
650 P. Th. Justesen: Zur Entwickelung und Verzweigung etc.

Helvetius, Mẻmoires de l'acadẻmie des sciences. Paris 1718.

Haller: Disputationes anatomicae. Gottingae 1750-51.

Derselbe: Elementa physiologica. 1761. Vol. III.

Derselbe: Anfangsgründe der Physiologie des menschlichen Körpers. Berlin 1766.

Soemmering: De corporis humani fabrica. 1800. Vol. VI.

Magendie: Vorlesungen über die physikalischen Erscheinungen des Lebens. Köln 1837.

Home and Bauer: Philosophical Transactions. 1827.

Bazin: Comptes rend. de l'acadénie royale des sciences. 1836. Vol. II.

Soemmering: Vom Baue des menschlichen Körpers ( $\mathrm{H} \mathrm{uschke).}$ $1841-44$.

Rossignol: Recherches sur la structure intime du poumon. Bruxelles 1846.

Schultz: Disquisitiones de structura et lectura canalium aëriferorum. Dorpat. 1850.

Milne-Edwards: Leçons de physiologyie. T. II. Paris 1857.

Stricker: Handbuch der Lehre von den Geweben.

Henle: Handbuch der Anatomie des Menschen، 2. Auf. 1873.

Ecker: Icones physiologicae. 'T. II. 1851-59. 